\title{
Reflejos de la influencia de la filosofía del lenguaje de Ludwig Wittgenstein en las teorías del Derecho en Kelsen, Ross, Hart y Dworkin
}

Reflections of the influence of Ludwig Wittgenstein's philosophy of language in the law theories of Kelsen, Ross, Hart and Dworkin

Autor: Antonio Sólon Rudá

DOI: https://doi.org/10.25058/1794600X.1786 


\title{
REFLEJOS DE LA INFLUENCIA DE LA FILOSOFÍA DEL LENGUAJE DE LUDWIG WITTGENSTEIN EN LAS TEORÍAS DEL DERECHO EN KELSEN, ROSS, HART Y DWORKIN*
}

\author{
Reflections of the influence of Ludwig Wittgenstein's \\ philosophy of language in the law theories of Kelsen, Ross, Hart \\ and Dworkin \\ Reflexões sobre a influência da filosofia da linguagem de \\ Ludwig Wittgenstein nas teorias do Direito em Kelsen, Ross, \\ Hart e Dworkin
}

Antonio Sólon Rudáa antoniosolonruda@gmail.com

Fecha de recepción: 29 de marzo de 2020 Fecha de revisión: 30 de marzo de 2020

Fecha de aceptación: 13 de mayo de 2020

\section{RESUMEN}

Este artículo, utilizando la metodología bibliográfica, se centra en la filosofía del lenguaje de Ludwig Wittgenstein a partir de sus principales obras: el Tractatus Logico-Philosophicus y las Investigaciones filosóficas, para analizar su influencia en las principales teorías de los autores más importantes del Derecho del siglo XX y principios de este siglo, como Kelsen, Hart, Ross y Dworkin, con la intención de que sea el punto de partida para la concepción de una forma alternativa de conceptualizar el Derecho, considerándolo como el significado de su uso en la sociedad que lo aplica.

\section{PALABRAS CLAVE}

Derecho; filosofía del Derecho; teoría del Derecho; filosofía del lenguaje, Wittgenstein.

\footnotetext{
* Artículo basado en la investigación realizada en el ámbito del máster en Teoría del Derecho, en la Facultad de Derecho de la Universidad de Lisboa. Agradezco a la profesora Isabel Silva Alves por la oportunidad de abordar un tema tan emblemático en el campo de la filosofía del derecho.

a. Abogado, Ph.D. student (Ciencias Penales en la Facultad de Derecho de la Universidad de Coimbra - Portugal); MSc student (Teoría del Derecho por la Facultad de Derecho de la Universidad de Lisboa, Portugal); Autor de la teoría significativa de la imputación. Véase en RUDÁ (2019).
} 


\section{ABSTRACT}

This article, by using bibliographical methodology focuses on the main works of Ludwig Wittgenstein's philosophy of language: Tractatus Lógico-Philosophicus and philosophical research to analyze its influence on the central theories of the most important legal authors in the XX century and at the begining of this century, such as Kelsen, Hart, Ross and Dworkin with the purpose of it becoming the starting point for an alternative way of conceptualizing Law, considering it as the meaning of its use in the society that applies it.

\section{KEY WORDS}

law, philosophy of law, theory of law, philosophy of language, Wittgenstein.

\section{RESUMO}

Este artigo, utilizando a metodologia bibliográfica, enfoca a filosofia da linguagem de Ludwig Wittgenstein a partir de suas principais obras: o Tractatus Logico-Philosophicus e as Investigações Filosóficas, para analisar sua influência nas principais teorias dos mais importantes autores do Direito. do século XX e início deste século, como Kelsen, Hart, Ross e Dworkin, com a intenção de que seja o ponto de partida para a concepção de uma forma alternativa de conceituar o Direito, considerando-o como o sentido de seu uso na sociedade que se aplica.

\section{PALAVRAS-CHAVE}

Direito; filosofia do direito; teoria da lei; filosofia da linguagem, Wittgenstein.

\section{INTRODUCCIÓN}

Hablando de los problemas filosóficos y las dificultades para resolverlos, Ludwig Wittgenstein (2009), el ámbito de su trabajo Investigaciones Filosóficas, considerado por muchos su principal, acuñó una de las frases más significativas para la filosofía moderna: "La filosofía es una lucha contra el embrujo de nuestro entendimiento por medio de nuestro lenguaje" (p, 109). En un análisis superficial del término "hechizar nuestro intelecto" no es difícil relacionarlo con la vanidad humana, y quizás esto es en gran parte responsable del número infinito de tesis y teorías que intentan explicar el Derecho, y quizás ahí radica el problema o, al menos, parte de él, porque el Derecho no debe explicarse sino describirse y aplicarse. Esta es la posición filosófica defendida por Ludwig Wittgenstein, para quien "Toda explicación tiene que desaparecer y sólo la descripción ha de ocupar su lugar" (p, 109).

Así, cuando Ludwig Wittgenstein propuso, en las Investigaciones Filosóficas, que "El significado de una palabra es su uso en el lenguaje" (2009: § 43), estaba haciendo mucho más que acuñar una de sus muchas frases, como era peculiar en él, una vez más estaba impactando enormemente la filosofía del lenguaje, como ya había sucedido cuando publicó el Tractatus, en el año 1921, cuando el filósofo vienés dio las bases para un nuevo pensamiento filosófico, señalando y demostrando que los problemas de la filosofía eran los embrollos que surgieron con el mal uso del lenguaje, y con eso, no solo inspiró a los filósofos de su tiempo ${ }^{1}$, abrió las puertas a una nueva forma de pensar el Derecho, con influenza en el Derecho en todo el mundo.

Por lo tanto, la idea positivista de un lenguaje puro, sin problemas y lógicamente perfecto, defendido en el Tractatus, y la idea del significado como uso, defendida en las Investigaciones filosóficas, hicieron la filosofía de Wittgenstein una referencia para muchos filósofos y teóricos del derecho, influyendo en muchos grupos de estudio, como el conocido círculo de Viena, con un sesgo positivista e inspirado en el Tractatus, y en la escuela de Oxford, inspirada en las Investigaciones filosóficas, donde se destacaron nombres como JL Austin, Gilbert Ryle, Peter Strawson y otros. También influyó en la modernización de la American Pragmatic School ${ }^{2}$, donde se destacaron nombres como Richard Rorty, además de Carnap, Kaufman y Zilsel, del Círculo de Viena.

No es raro que una corriente filosófica reemplace a otra como base metodológica para la concepción de un nuevo Derecho, que influye directamente en todas las ramas del derecho, ya sea público o privado. En este campo, de vez en cuando, parece que lo que tenía sentido, ya no lo

1. Como ejemplo, Hans Kelsen, quien, utilizando el positivismo lógico de Wittgenstein, revolucionó e influyó en la forma de pensar sobre el Derecho, con su teoría pura del Derecho, como veremos a su vez.

2. Donde el pragmatismo tiene el significado de una idea como el conjunto de sus desarrollos prácticos. 
tiene y, por eso, estamos obligados a pensarlo de nuevo, de manera diferente.

Este es un fenómeno que no ocurre solo en nuestra época, también fue así en tiempos cuando grandes nombres que construyeron el pensamiento filosófico de la humanidad se atrevieron a creer en sus ideas. No necesitamos ir muy lejos, porque a principios del pasado siglo, por ejemplo, mientras las facultades de Derecho y Filosofía formaban a nuevos estudiantes, en algún rincón de algunas universidades, jóvenes investigadores se atrevieron a desafiar el Derecho basado en la metafísica, utilizando como instrumento el positivismo lógico y estructurado ${ }^{3}$.

A mediados del mismo siglo, otro grupo de investigadores desafió a los lógicos y construyó un Derecho basado en una nueva forma de pensar el mundo desde la filosofía del lenguaje común, mientras las Facultades aún ni habían adaptado e incorporado a sus cursos las metodologías del positivismo lógico del Círculo de Viena. Esta realidad muestra cuán perjudiciales pueden ser el conservadurismo y los dogmas para la formación de nuevos filósofos, en vista del dinamismo y la evolución del conocimiento.

En este contexto, es difícil imaginar las razones por las cuales muchas facultades de Derecho aún no han adoptado en el plan de estudios de sus cursos de posgrado, y especialmente, en las de licenciaturas en Derecho, a filósofos como Ludwig Wittgenstein, Austin y muchos otros, que desempeñaron un papel destacado en la construcción del Derecho actual.

Es un hecho que el campo del trabajo filosófico está fuertemente impulsado por investigaciones que apuntan a la influencia de Wittgenstein en el pensamiento de los grandes teóricos del derecho, como los que se han citado. Dentro de los muchos textos importantes usados para construir esto, como ensayos, disertaciones y tesis, se revisó con especial énfasis en el ensayo del profesor David Barbosa Oliveira, de la Universidad de Ceará, por haber sido el primero con quien el investigador contacto y lo que motivó a desarrollar el tema (influencia wittgenstiana).

Lo que es seguro es que Wittgenstein se consustancia cada vez más como fuente de

\footnotetext{
3. El ejemplo principal fue el Círculo de Viena.
}

iusteorías, y cada uno bebe sus ideas de la manera que más le conviene. El problema es que, extrañamente, muchos de los que bebieron de su filosofía intentan no dejar rastros, y a veces se esfuerzan por mostrar solo una ligera aproximación, pero las evidencias no les permiten esconderse en los embrollos teóricos que inventan, ya que es prácticamente imposible para cualquier teórico ignorar a Wittgenstein después de estudiar su filosofía, porque sus ideas impactan e imponen una nueva forma de pensar sobre el lenguaje y el mundo.

Hay quienes, después de beber su néctar filosófico inagotable, intentan ignorarlo e incluso deplorarlo, insultándolo, en un intento infructuoso por hacerlo irrelevante, como lo hizo Bertrand Russell ${ }^{4}$.

En este trabajo, no percibirán una profundidad dogmática en las teorías que surgirán durante el desarrollo, ya que lo que se quiere es señalarlas como una fuente $y$ referencia meramente argumentativa de lo que se pretende abordar, que es la influencia que cada una de ellas sufrió de la filosofía del lenguaje común, de Ludwig Wittgenstein, principalmente con respecto a una lenguaje lógicamente perfecta (pura) y al significado como uso, especialmente porque, tanto en filosofía como en derecho, no se menciona

4. Me refiero aquía las críticas de Bertrand Russel, en el trabajo My Philosophical Development, en un momento en que Wittgenstein ya no existía, sino solo su filosofía de Investigaciones filosóficas que floreció de manera sorprendente y dominó las discusiones sobre filosofía en Oxford, donde encontró una útil casa de guardia. Russell, un gran amigo y aliado de antaño, no dejó atrás todo ese éxito post mortem y destiló su veneno más puro sobre el trabajo de Wittgenstein. Por supuesto, no sirvió de nada, porque fue útil para hacer que Wittgenstein se destacara aún más, porque para ese momento Russell ya era conocido en todo el mundo, ya que había recibido el Premio Nobel de Literatura en el año 1950. Por lo tanto, según Bertrand Russell, hablando sobre Wittgenstein y su trabajo Investigaciones filosóficas, dice que: "Tus doctrinas positivas me parecen triviales y tus doctrinas negativas son infundadas. No encontré nada que parezca interesante en las Investigaciones filosóficas de Wittgenstein y no entiendo por qué toda una escuela encuentra sabiduría importante en sus páginas. El primer Wittgenstein, con quien me encontré íntimamente, fue un hombre apasionado por el pensamiento intenso, profundamente consciente de la dificultad de esos problemas que, como él, apreciaba la importancia y que poseía (o al menos eso creía) un verdadero genio filosófico. El último Wittgenstein, por otro lado, parecía cansado de pensamientos serios e inventó una doctrina que haría innecesaria esa actividad. Ni por un momento creí que la doctrina que tiene consecuencias tan flojas es cierta. Sin embargo, me doy cuenta de que tengo una predisposición inmensamente fuerte contra ella, porque si es verdad, la filosofía es, en el mejor de los casos, una pequeña ayuda para los lexicógrafos y, en el peor, un entretenimiento inactivo en la mesa de café". (Russell, 1959: 216-217). 
a ningún autor o autora que sea totalmente correcto, sino a concepciones innovadoras, es decir, de ideas nuevas y divergentes que son, de hecho, un factor imprescindible para el avanzo científico.

Según el filósofo alemán Karl-Otto Apel (1922 - 2017), los tres paradigmas de la filosofía son: el ontológico (Platón a Aristóteles); la filosofía de la conciencia (Husserl y Descartes); y el giro lingüístico (Peirce y Wittgenstein), (Apel, 2013). En particular, eliminaría a Peirce de esta lista, con la venia necesaria, por supuesto, porque a pesar de su importancia para el pragmatismo, fue Wittgenstein quien estableció el verdadero paradigma. Y dos veces. Una, al romper con el viejo modelo de pensamiento sobre filosofía y, luego, yendo en contra de todo lo que defendió (lenguaje privado y lógicamente perfecto), creando otra forma de pensar sobre la filosofía a partir de la idea del significado como uso. Entonces, aunque Peirce es solo uno más en medio de una corriente filosófica (lenguaje), Wittgenstein es, digamos, la "estrella" más brillante de la filosofía contemporánea, y eso no es poca cosa.

Como herramientas metodológicas para la preparación de este trabajo, se usaron la investigación bibliográfica y la dialéctica, dada la necesidad de dialogar con una buena parte del pensamiento teórico-jurídico de los principales filósofos del derecho que se basan en la filosofía del lenguaje común de Wittgenstein. Por lo tanto, saber qué hay de nuevo en la Filosofía del Derecho y hacia dónde se dirige el Derecho son preguntas para las que no hay una respuesta objetiva, y es posible que no la haya, pero tal vez sea mejor de esta manera, que ni siquiera debería haber una respuesta lista, bajo pena de no existir la propia búsqueda $\mathrm{y}$, consecuentemente, de no existir más la investigación científica y metodológica.

\section{LA INFLUENCIA DE LA FILOSOFÍA DEL LENGUAJE DE LUDWIG WITTGENSTEIN EN LAS TEORÍAS DEL DERECHO EN KELSEN, ROSS, HART Y DWORKIN}

\section{CONSIDERACIONES PRELIMINARES}

Mucho se ha discutido hoy en los bancos de la Facultad sobre las teorías del derecho positivista y postpositivista, haciendo que sus autores se conviertan en verdaderas celebridades desde sus concepciones, monopolizando la discusión sobre las direcciones del Derecho, sobre la mejor o peor ley, considerando sus conceptos de ética, moral, derecho y justicia. Sin embargo, la pregunta es: ¿Cuál es la base filosófica utilizada por estos filósofos? ¿Quién los influenció?

En objetivo de este capítulo es mostrar y analizar en qué medida los autores famosos de filosofía y teoría del derecho fueron influenciados por la filosofía del lenguaje de Ludwig Wittgenstein y la utilizaron como base en sus concepciones, y para eso, nos centraremos en las más conocidas teorías de Kelsen, Ross, Hart y Dworkin, al concebir sus teorías y suposiciones de lo que actualmente se llama nueva ciencia jurídica.

\section{LA TEORÍA PURA DEL DERECHO DE KELSEN, DESDE EL TRACTATUS LOGICO-PHILOSOPHICUS.}

El desarrollo científico y del conocimiento en su conjunto se lleva a cabo a partir de la transformación de lo que ya existe ${ }^{5}$, de lo que ya se pensó, es decir, surge un nuevo pensamiento en un intento de mejorar lo que ya existe $y$, en muchos casos, desafortunadamente, no ocurre. Con esto quiero decir que el conocimiento depende del conocimiento, por pequeño que sea, para que pueda generarse.

\subsection{KELSEN BAJO LOS REFLEJOS DE LA FILOSOFÍA DEL TRACTATUS LOGICO- PHILOSOPHICUS - LA BÚSQUEDA DE UN LENGUAJE IDEAL Y LÓGICAMENTE PERFECTO}

Al igual que Saussure en el lenguaje, Kelsen busca alejarse del Derecho con un sesgo filosófico y sociológico, buscando valorar la idea de una ciencia del derecho, es decir, de una ciencia pura del derecho. Por lo tanto, además de partir de las concepciones de Ferdinand Saussure, estará más que inspirado por Wittgenstein, adoptará muchas de sus posiciones contenidas en el Tractatus.

5. Como dije Lavoisier: "En la naturaleza no se crea nada, nada se pierde, todo se transforma". Todavía hay referencias a esta misma máxima, pero, en otras palabras, agrega que: "Nada se pierde, nada se crea, todo se transforma" (R. Taton, Histoire générale des sciences, t. I, París, Presses Universitaires de France, $1957, p$. 217). Esta frase también se atribuye a Lavoisier, sin embargo, fue inspirada por el filósofo presocrático Anaxágoras quien escribió: "Nada nace ni perece, pero las cosas existentes se combinan, luego se separan nuevamente". (Franckowiak, 2017 :2). 
Es cierto que Wittgenstein, en el Tractatus, buscó y apoyó la idea de un lenguaje perfecto, cuyo significado, también perfecto, era lo que debería importar. La búsqueda de un discurso (lenguaje) racionalmente perfecto y libre de impurezas lingüísticas, se suma al deseo del joven Wittgenstein, que coqueteará con las matemáticas y tendrá una lógica como compañera, un aliado de primera magnitud para enfrentar la metafísica que reinaba en la filosofía de la época. Estas ideas sirvieron de base para los filósofos del Círculo de Viena y su positivismo lógico o neopositivismo. Esta idea innovadora del lenguaje como objeto y su estudio llevado a cabo utilizándola como herramienta en sí (metalenguaje) fue fundamental para que Kelsen desarrollara su Teoría Pura del Derecho. Se podría decir que el neopositivismo defendido por Wittgenstein fue importado por Kelsen y su pensamiento científico-filosófico. Sobre esto, vale la pena traer la lección del joven Dr. Fossi aquí, que agregará que:

El pensamiento de corte analítico tiene sus inicios en el círculo de Viena, ellos instauraron una corriente de pensamiento denominada empirismo lógico, que tenía por característica fundamental reducir la filosofía a análisis lógico del lenguaje. Desarrollada bajo la influencia de Ludwig Wittgenstein (de su primera versión), quien sostenía que la labor de la filosofía se resumía en la clarificación lógica de las ideas. A partir de allí, se desarrolló el gran aporte teórico del mayor jurista del siglo XX, Hans Kelsen, con la denominada teoría pura del derecho (Fossi, 2014: 43).

Esta primacía de la pureza del significado del análisis jurídico se puede observar en Kelsen, cuando usa el término "puro" para calificar su propia teoría 6 . Según él: "cuando ella se llama a sí misma una teoría pura del derecho", esto significa que tiene la intención de garantizar el conocimiento solo dirigido al Derecho y excluir de este conocimiento todo lo que no pertenece a su objeto, todo lo que no se puede, rigorosamente, determinar como Derecho"7.

6. Desde el prefacio hasta su primera edición, Kelsen dirá que su teoría está "depurada de toda ideología política y de todo elemento de las ciencias de la naturaleza, y consciente de tener un objeto regido por leyes que le son propias" (2009: 13).

7. Para este autor, "El principio fundamental de su método es, pues, eliminar de la ciencia del derecho todos los elementos que le son extraños" (Kelsen, 2009: 19).
Kelsen, autor de la idea de la jerarquía de las normas jurídicas, busca un concepto de Derecho con la intención de "liberar la ciencia jurídica de todos los elementos que le son extraños"8. Esto está justificado, según Kelsen, porque "cuando se llama a sí misma una "pura" teoría del derecho", esto significa que tiene la intención de garantizar el conocimiento solo dirigido a la ley y excluir de este conocimiento todo lo que no pertenece a su objeto, todo no puede determinarse estrictamente como un derecho" (1999: 1).

Al luchar por un derecho libre de sus "impurezas", Kelsen muestra que, para él, la ciencia del Derecho no es más que un conjunto de datos que describe normas jurídicas positivas. La actividad científica del derecho es exactamente el acto de describir (y no crear) estas normas ${ }^{9}$.

Como enseña Oliveira, en Kelsen "las proposiciones o declaraciones que la Ciencia Jurídica analiza deben distinguirse, como proposiciones jurídicas de las normas jurídicas producidas por los cuerpos jurídicos" (Oliveira, 2017: 37). Según este autor, "las proposiciones jurídicas son, para Kelsen, juicios hipotéticos que enuncian y, bajo ciertas condiciones, producen una cierta consecuencia jurídica; considerando que las normas legales no son juicios, sino mandatos imperativos"10. Tales concepciones están presentes en los postulados neopositivistas del Círculo de estudio que fue influenciado por el Wittgenstein del Tractatus, donde buscó, a través del positivismo lógico, deshacerse de las impurezas que obstaculizaron la filosofía y que se evidenciaron en especulaciones metafísicas, lo cual debe evitarse, principalmente debido a la ausencia de rigor científico defendido por esta corriente filosófica.

A partir de la distinción entre lenguaje objeto (lenguaje como objeto de estudio) y metalenguaje, Kelsen defenderá que las proposiciones o anuncios analizados por la Ciencia Jurídica, como proposiciones jurídicas, se distinguen de las normas producidas por los cuerpos jurídicos. Para él, el hecho de que la Ciencia Jurídica describa el

8. Mientras en el Tractatus, WITTGENSTEIN dijo que tenía la intención de liberar a la filosofía de sus lazos metafísicos.

9. Ver la brillante tesis de maestría de Maia (2006).

10. Para Kelsen, porque a Ciência Jurídica "descreve o Direito; ela não pode, como o Direito produzido pela autoridade jurídica (através de normas gerais ou individuais) prescrever seja o que for" (Oliveira, 2017: 37). 
Derecho no puede, como el Derecho producido por la autoridad jurídica, prescribir nada (Kelsen, 1999: 52). Según el autor: "Ningún jurista puede negar la distinción esencial que existe entre una ley publicada en el periódico oficial y un comentario legal sobre esa ley, entre el código penal y un tratado de derecho penal" (Kelsen, 1999: 52). Para él,

La distinción se revela en el hecho de que las proposiciones normativas formuladas por la ciencia jurídica, que describen el Derecho y que no atribuyen ningún deber o derecho a nadie, puede ser verdadero o falso, mientras que las reglas de deber ser, establecidas por la autoridad jurídica - y que asignan deberes y derechos a los sujetos jurídicos - no son verdaderas o falsas, sino válidas o inválidas, así como los hechos del orden del ser no son verdaderos ni falsos, pero solo existe o no existe, solo las declaraciones sobre estos hechos pueden ser verdaderas o falsas (Kelsen, 1999: 52).

En otro giro, al afirmar en el Tractatus que "La figura tiene en común con lo figurado la forma lógica de figuración" (Wittgenstein, 2008: $\S 2.2$ ), Wittgenstein dice que la forma lógica debe ser el punto central y común entre el lenguaje y su objeto. Para Maia, 2006, "Kelsen quiere decir que, aunque las proposiciones reflejan la naturaleza del deber ser del objeto (la forma lógica de Wittgenstein), su carácter sigue siendo meramente descriptivo, como deberían ser las proposiciones jurídicas hechas por la ciencia" (p, 65). Para este autor, en Kelsen, las proposiciones jurídicas "deben tener una forma lógica en común con su objeto (la norma jurídica). De lo contrario, la ciencia del Derecho tendría la culpa en la construcción del conocimiento"( $p, 66)$.

Maia, sabiamente, nos lleva a importantes puntos de congruencia entre Kelsen y Wittgenstein, al agregar, por ejemplo, que "la postura de Kelsen con respecto a la negación de valores como una descripción científica válida es la misma postura encontrada en el Tractatus de Wittgenstein sobre el tema" (Maia, 2006: 69). Según este autor, "ni Kelsen (1999, p.1) ni Wittgenstein niegan la existencia de valores. Lo que se niega es que podamos hablar de ellos o, en el caso de Kelsen, incorporarlos en un campo de conocimiento científico" (p, 69). Para Maia, "la teoría del derecho, para mantenerse pura, no estudia el derecho a través de los valores, la ética, sino únicamente a través de los hechos, la validez. Esta dualidad, presente en Kelsen y Wittgenstein, es una consecuencia inevitable de la función descriptiva y avaladora de la realidad" (Maia, 2006: 69). Esta posición se puede ver en Kelsen, 1999, cuando se trata de valor moral en el contexto de la ciencia jurídica. Según este autor, "aunque las normas jurídicas, como prescripciones del deber ser, constituyen valores, la tarea de la ciencia jurídica no es en modo alguno una valoración o apreciación de su objeto, sino una descripción ajena a los valores (wertfrei)" (p, 48). Para Kelsen, "el jurista científico no se identifica con ningún valor, ni siquiera con el valor jurídico que describe" $(p, 48)$.

La negación de Kelsen del uso de valores naturalmente impone una limitación al acto de interpretar desde la teoría pura del derecho, y la consecuencia es el uso del conocido "marco" idealizado por este autor, que aumentará el rango de aplicación del Derecho, desde varias hipótesis manejadas por él. Según Kelsen, "El Derecho para aplicar forma, en todas estas hipótesis, una moldura dentro del cual existen varias posibilidades de aplicación, de modo que cualquier acto que permanezca dentro de este cuadro o moldura, que llene este marco en cualquier sentido posible, está en conformidad con el Derecho"11.

La defensa de una ciencia jurídica sin valores está en línea con lo que Wittgenstein propone en el Tractatus, cuando se trata de proposiciones relacionadas con el significado del mundo. Para Wittgenstein, "Todas las proposiciones tienen igual valor"(2008: § 6.4). Según él, "El sentido del mundo debe quedar fuera del mundo. En el mundo todo es como es y sucede como sucede: en él no hay ningún valor, y aunque lo hubiese no tendría ningún valor" (2008: § 6.42). Para Wittgenstein del Tractatus, no puede haber

11. Para Kelsen, "si "interpretación" significa la fijación cognitiva del significado del objeto a interpretar, el resultado de una interpretación jurídica solo puede ser la fijación del marco que representa el Derecho a interpretar y, en consecuencia, el conocimiento de las diversas posibilidades que existen dentro de esta moldura" (Kelsen, 1999: 247). A pesar de la infinidad de argumentos que podrían hacerse aquí acerca de esta solución encontrada por Kelsen para enfrentar la imposición hecha por su teoría pura del derecho, en los términos que mencionamos, es solo en el trabajo de investigación específico sobre interpretación que llevaremos a cabo en el contexto de una hermenéutica constitucional que analizaremos con mayor profundidad sobre este tema. 
proposiciones en ética, ya que no pueden expresar nada más elevado(2008: $§ 6.42)$.

No podemos cerrar este tema sin estar a la altura del juego de palabras de Maia, según el cual, para "Kelsen, haces ciencia o hablas de valores. Para Wittgenstein, o hablas de algo con significado, o debes guardar silencio. En ambos casos, no hay espacio para un discurso valorativo" (Maia, 2006: 71). De esta manera, no se pudo hacer una mejor definición o juego de palabras al respecto.

\section{LA INFLUENCIA DE WITTGENSTEIN SOBRE ALF ROSS, DESDE LA IDEA DEL SIGNIFICADO.}

\subsection{EL SEGUNDO WITTGENSTEIN COMO BASE FUNDAMENTAL PARA EL PENSAMIENTO DE ROSS.}

Como vimos ${ }^{12}$, la transición del primero al segundo Wittgenstein estuvo marcada por una profunda ruptura en su pensamiento, en su forma de pensar acerca de los problemas filosóficos: los mismos problemas que él pensó que había resuelto. Si antes, en el Tractatus, pensaba que el significado de una oración era la forma en la que se podía verificar que era verdadero o falso, ahora tenía muy claro que el significado de una oración determinada era su uso en el lenguaje (Wittgenstein, 2009: § 43), es decir, en el contexto lingüístico.

Las nuevas preocupaciones de Wittgenstein estaban ligadas a saber cómo funciona el lenguaje

12. Aun habiendo mencionado el cambio radical en el pensamiento del primer al segundo WITTGENSTEIN, nada podría ser más claro que el propio autor diciendo lo que yo llamo un 'punto de inflexión' en su pensamiento, y lo hace en Wittgenstein 2009: § 109. Según él "Era cierto que nuestras consideraciones no podían ser consideraciones científicas. La experiencia 'de que se puede pensar esto o aquello, en contra de nuestros prejuicios' - sea lo que fuere lo que esto pueda querer decir - no podría interesarnos. (La concepción neumática del pensamiento). Y no podemos proponer teoría ninguna. No puede haber nada hipotético en nuestras consideraciones. Toda explicación tiene que desaparecer y sólo la descripción ha de ocupar su lugar. Y esta descripción recibe su luz, esto es, su finalidad, de los problemas filosóficos. Estos no son ciertamente empíricos, sino que se resuelven mediante una cala en el funcionamiento de nuestro lenguaje, y justamente de manera que éste se reconozca: a pesar de una inclinación a malentenderlo. Los problemas se resuelven no aduciendo nueva experiencia, sino compilándolo ya conocido. La filosofía es una lucha contra el embrujo de nuestro entendimiento por medio de nuestro lenguaje". y su interacción con la acción humana ${ }^{13}$. El pensamiento filosófico de Wittgenstein comienza a considerar más las formas de vida, la persona humana, dejando de lado todo el rigor lógico impuesto en el Tractatus y en el que Kelsen buscó inspiración. Y es en este nuevo entorno de la filosofía del lenguaje que Ross guiará una buena parte de su pensamiento y su concepto de Derecho.

\subsection{EL FENÓMENO JURÍDICO COMO FENOMENO SOCIAL DESDE LA FILOSOFÍA DEL LENGUAJE ORDINARIO.}

A partir del cambio radical en el pensamiento de Wittgenstein, Ross comenzó a adoptar preguntas relacionadas con la filosofía del lenguaje ordinario para pensar sobre el Derecho de una manera diferente del pensamiento de Kelsen, que se basaba en el pensamiento del primero Wittgenstein. Ross comienza a pensar en los fenómenos jurídicos como fenómenos sociales, aparentemente alejándose de la abstracción normativa que Kelsen idealizó del Tractatus.

Desde el nuevo pensamiento de Wittgenstein sobre su teoría del significado como uso, se dirá que entender una oración significa entender un idioma y que entender un idioma significa dominar una técnica (Wittgenstein, 2009: § 199), Alf Ross, al decir que "el lenguaje puede manifestarse como una serie de formas auditivas o visuales (habla y escritura)" se refiere a los dictados de Wittgenstein, como lo había hecho antes al tratar con los colores de las luces. Con respecto a tales formas, Ross dirá que el significado que se les atribuye es claramente convencional y que nada impedirá que la palabra "gato", por ejemplo, se use para designar al animal doméstico de cuatro patas que hace "wow, wow" y perro para designar lo que hace "miau" (Ross, 2000: 140). Según él, "el significado atribuido a los símbolos lingüísticos está determinado por las costumbres de la comunidad con respecto a las circunstancias en las que se considera apropiado emitir ciertos sonidos"(Ross, 2000: 140). Simplificando la comprensión, es posible decir que el significado de los símbolos lingüísticos está

13. Como explica Oliveira: "el lenguaje se considera un tipo de acción, de modo que la consideración del lenguaje no puede separarse de la consideración de la acción humana o la consideración de la acción ya no puede ignorar el lenguaje" (Oliveir, 2006: 138). 
determinado por su uso en la comunidad ${ }^{14} \mathrm{y}$ de acuerdo con las circunstancias relacionadas con el caso específico.

En la introducción al Tractatus de Wittgenstein, su entonces amigo Bertrand Russell dice que "La función esencial del lenguaje es afirmar o negar los hechos. Dada la sintaxis de un lenguaje, el significado de una proposición está determinado tan pronto como se conozca el significado de las palabras que la componen"15. En el mismo prólogo dirá que " La serie de palabras es un hecho, tanto como pueda serlo aquello que hace que sea verdadera o falsa"16. Para Russell, "La relación entre estos dos hechos no es inanalizable, puesto que el significado de una proposición resulta del significado de las palabras que la constituyen. El significado de la serie de palabras que es una proposición es una función del significado de las palabras aisladas"17. Contra esta concepción, Ross dirá que "las palabras individuales carecen de significado independiente, teniendo solo un significado abstraído de las expresiones en que aparecen"18. Este autor llamará la atención sobre la importancia de enfatizar lo que dijo, porque según él, "de lo contrario, uno puede caer fácilmente en el error de pensar que el significado de una expresión es el resultado de la suma total de los significados de los campos individuales que la forma", que, como vimos en la introducción

14. Véase infra cuando hablarnos de Dworkin o en Wittgenstein, 1982: 203.

15. Wittgenstein, 2009: Introducción.

16. Wittgenstein, 2009: Introducción.

17. Wittgenstein, 2009: Introducción.

18. El autor trae el ejemplo del gato, parafraseando a Wittgenstein, que usa el término "palabra". Veamos: de acuerdo con Wittgenstein, "...si la oración me puede parecer como una pintura en palabras, incluso cada una de las palabras en la oración como una figura, entonces ya no es de extrañar que una palabra, pronunciada aisladamente y sin propósito, parezca llevar en sí misma un determinado significado." (Wittgenstein, 2009: XI). A su vez, Ross agregará que "si alguien dice gato de forma aislada, no significa nada. No es una expresión, a menos que la palabra, de acuerdo con las circunstancias (por ejemplo, si olfateo el aire y miro con curiosidad) pueda interpretarse como una forma abreviada de un juicio como "debe haber un gato cerca" (Ross, 2000: 141). Tenga en cuenta que la negación de Ross de la segunda concepción de Wittgenstein y no la primera (se alinea con Ross) es solo relativa, ya que dice que depende de las circunstancias, está diciendo en realidad que depende del contexto. De esta manera, caemos en el concepto constante en el aforismo 43 de Investigaciones y ya aquí tan a menudo dicho en este trabajo, que es: "el significado de una palabra es su uso en el lenguaje". Por lo tanto, tenemos la esencia del pensamiento Wittgenstiano utilizado y aplicado también por Ross y para el "bien" de su concepción jurídica. Esta concepción será confrontada antes de este postulado, pero en el trabajo futuro, ya mencionado. de Russell al Tractatus de Wittgenstein, es una concepción del primer trabajo de Wittgenstein. Es evidente, entonces, que el pensamiento de Ross ya está más en línea con el de Wittgenstein de Investigaciones filosóficas.

Ross, basándose en las costumbres lingüísticas mencionadas en su ejemplo de las palabras "gato" y "perro" y en las costumbres de la comunidad imaginada, dirá que "las costumbres o normas lingüísticas que establecen la función simbólica del lenguaje solo pueden descubrirse a través de un estudio por el cual las personas se expresan". Para Ross, por expresión tenemos "la unidad lingüística mínima que tiene significado por derecho propio"(2000: 141). La frase, por ejemplo: "mira, es un gato" es una expresión. Según él, "es, en su integridad, el portador de un significado"( 2000: 141). Su conclusión es que "la comunicación lingüística entre los seres humanos se produce a través de tales unidades $y$, en consecuencia, deben constituir el punto de partida para el estudio de la función simbólica del lenguaje"(2000: 141).

Es por eso por lo que, para Ross, el juez no es un autómata y siempre debe elegir un posible significado que sea útil para la comunidad, juzgando así con apoyo en un sentido de justicia. Por lo tanto, para él: "El Derecho no se reduce a las leyes creadas por la autoridad y la actividad del juez no se limita a su aplicación mecánica, ya que esto es imposible, ya que el fenómeno legal es, para Ross, a partir de Wittgenstein, un juego de lenguaje" (Oliveira, 2017: 39). De hecho, es a partir de la idea de los juegos de lenguaje, considerando estos como un conjunto de reglas establecidas por un grupo de hablantes que permiten la existencia y el uso del lenguaje en sí, Ross dirá que "el juez no está motivado exclusivamente por las normas jurídicas; también es el caso para fines sociales y para el discernimiento teórico de conexiones sociales relevantes para lograr esos fines" (Ross, 2000: 43).

\section{EL DERECHO EN HART DESDE WITTGENSTEIN.}

\subsection{CONSIDERACIONES PRELIMINARES}

En el escenario de la doctrina de Ross, Hart también tomará las concepciones del Segundo Wittgenstein como punto de partida, 
especialmente con respecto a los juegos de lenguaje. Este filósofo estará interesado en comprender los juegos de lenguaje en los que funciona una palabra determinada y cuáles son las diferencias entre el juego de lenguaje en el que se inserta y otros juegos de lenguaje determinados por el acto de seguir las reglas como instituciones sociales (Oliveira, 2017: 39). Como dice Oliveira, "En el Derecho, no siempre es posible saber con precisión cómo o qué regla seguir, de modo que las reglas del juego solo dan dirección, y los participantes deben descubrir cómo funcionan en un contexto específico" (Oliveira, 2017: 39).

Sin embargo, el desarrollo más evidente de la Filosofía del Lenguaje Ordinario en el pensamiento de Hart es su idea de discrecionalidad judicial, donde mantendrá que ante reglas imprecisas el juez deberá actuar discrecionalmente. Con respecto a este desarrollo, Stolz dirá que está fundamentado "en la concepción hartiana sobre la textura abierta del lenguaje y, en particular, el lenguaje jurídico que, en algunas ocasiones, establece normas legales que contienen términos genéricos, vagos y controvertidos" (Stolz, 2007: 111).

De una manera mucho más clara, Machado dirá que "a través de la visión dinámica del lenguaje de Wittgenstein, Hart se dio cuenta de que el Derecho está compuesto de reglas de varios tipos, cuyos conceptos tendrían que determinarse por su uso, y no por construcciones doctrinarias y abstractas" (Machado, 2015: 112). ${ }^{19}$

También según Machado,

La idea, originada en Wittgenstein, de que el lenguaje no expresa una realidad ideal y abstracta, previa a ella, sino que construye la realidad social, a través de significados $\mathrm{y}$ conceptos que solo pueden investigarse a través de su uso, y luego se cargan con intencionalidad, lleva a Hart a cuestionar los conceptos jurídicos construidos de manera

19. Por nuestra parte, tendemos a creer que el uso del término "textura abierta", tanto por Waismann, en la filosofía del lenguaje como más tarde por Hart, en derecho, es un ejemplo completo del viejo dicho "vestirse con ropa nueva", o en otras palabras, es el mismo problema, sea cual sea el nombre que desee, ya sea "porosidad", como lo hizo Waismann; "Textura abierta", como lo hizo el Sr. Kneale, y que luego fue utilizada por tantos autores, de hecho, lo que tenemos es lo mismo, es decir: una propuesta defectuosa, débil y poco convincente, de la cual no se extrae la excelencia que originalmente se pretendió, ya que funciona como una "base" para la exacerbación de la discreción de los jueces. abstracta y el concepto del derecho mismo (2015: 120).

Basado en esta idea originalmente presentada por Waismann (1951) sobre los conceptos empíricos que no están delimitados en todas las direcciones posibles, y que ningún concepto está delimitado para que no haya espacios para dudas sobre su significado, entendiendo por textura abierta, una palabra que no fue diseñada para usarse en todas las situaciones posibles que pudieran surgir (Struchiner, 2001: 11-13) , Hart (2009) dirá que "todo sistema legal deja abierto un campo vasto y muy importante para que los tribunales y otras autoridades puedan usar su discreción para los más vagos los estándares inicialmente vagos" (p, 176).

Por lo tanto, en la textura abierta, lo que tenemos realmente es una indeterminación del lenguaje frente a la necesidad del sistema jurídico que se puede verificar por la falta de claridad de lo pretendía el legislador, lo que perjudica todo caso específico. Pero, por lo tanto, más que nunca existe la necesidad de una interpretación del significado a partir del uso de la palabra en la frase u oración en el contexto en el que se inserta.

Antes de entrar directamente en la influencia de Wittgenstein sobre Hart, es necesario hacer algunas consideraciones sobre la forma en que esto ocurrió, así como los matices que lo involucran.

La influencia de Wittgenstein en Hart no es algo disfrazado, como en muchos otros teóricos del Derecho. Como dice Narváez Mora, "el pensamiento de Hart está relacionado con el de Wittgenstein, debido al contexto filosófico de la obra del primero" (Narváez Mora, 2004: 195) ${ }^{20}$. Narváez señala al menos tres elementos teóricos que estarían presentes en el trabajo de Hart: la

20. Un ejemplo de esto es la cita que hace de Wittgenstein en la pág. 258 (Notas), por Hart (1994), cuando trata de "semejanza de familia", y agrega que: "la recomendación de Wittgenstein" [(2009), \$\$ 66 y ss], "es especialmente relevante para el análisis de términos legales y políticos. Considerando la definición de "juego", escribió: "No digas que debe haber algo en común o no se llamarían" juegos ", pero mira y ve si hay algo en común para todos. Porque si los miras, no verás nada común para todos, excepto similitudes, relaciones y toda una serie de ellos". Según este autor, "estas influencias en los supuestos filosóficos del jurista inglés tienen en común haber supuesto una renovación en el tratamiento filosófico de la comprensión de las acciones (también lingüísticas) a través de las ideas de regla y seguimiento de reglas". (2009: 196). 
filosofía del lenguaje presente en Austin, 1962 (How to do things with words); los trabajos en ciencias sociales, extraídos de la obra The idea of a Social Science, de Winch (1990); y la filosofía del lenguaje de Waismann (1951), especialmente su concepción de la textura abierta en el lenguaje.

Narváez Mora, haciendo uso de una rica fuente bibliográfica, hace algunas consideraciones importantes sobre el entrelazamiento de la doctrina traída por Hart y la filosofía del lenguaje ordinario, de Wittgenstein. Según ella, el hecho de que Hart pertenezca a la corriente de la filosofía del lenguaje ordinario, a pesar de que estaba, concretamente, en el ámbito del Derecho, sirvió para que las asociaciones con la filosofía del segundo Wittgenstein fueran frecuentes en su trabajo.

En cualquier caso, la verdad es que no hay forma de hablar sobre la influencia de Wittgenstein en la teoría del derecho de Hart, sin tratar primero dos temas sensibles a este asunto, que en realidad son concepciones a partir de las cuales comenzamos. Primero, que es innegable que la idea de reglas en el contexto social, desde el contexto lingüístico de su aplicación, se origina en Wittgenstein; segundo, que no fue Hart quien acuñó el término "textura abierta", sino lo que mejor supo aprovechar una idea planteada por Waismann (1951), quien tampoco fue el autor de ese término, pero, junto con Wittgenstein, de quien era amigo, sirvió de inspiración a Hart; $y$, tercero, que no solo Wittgenstein influyó directamente a Hart, ya que no podemos dejar de mencionar que Waismann, amigo de Wittgenstein, se unió al austriaco como una gran referencia para el concepto de derecho desarrollado por Hart, especialmente la idea de una textura abierta en el Derecho. Luego procedo a explicar estos supuestos.

\subsection{DE LA IDEA DE REGLA (DE WITTGENSTEIN A HART).}

Aun en el Tractatus, cuando criticó la teoría de los tipos de Bertrand Russell, Wittgenstein trata sobre las reglas por primera vez, y lo hace para decir que el error de Russell se revela en el hecho de que tuvo que hablar sobre el significado de los signos para establecer reglas para dichos signos (2008: § 3.331). Según Wittgenstein, en el contexto de las sintaxis lógicas, "el significado de un signo no debe nunca desempeñar ningún papel; el significado debe poder establecerse sin que haya por ello que hablar del significado de un signo; debe solo presuponer la descripción de la expresión" (2008: § 3.330).

Las reglas de sintaxis lógica, según Wittgenstein, deben ser inteligibles por sí mismas, siendo suficiente saber cómo se designa cada signo, es decir, lo que significan (2008: § 3.334). En esta idea, existe la noción de que las reglas deben ser claras y hablar por sí mismas, por lo tanto, no necesitan ser interpretadas y sometidas a ningún tipo de argumento o discreción innecesaria.

No se puede dejar de relacionar la idea de que hay agujeros en las leyes, o, en un lenguaje más apropiado, quiero decir, alineado con las teorías de Waismann y más tarde de Hart, que hay texturas abiertas en las leyes, con la idea de Wittgenstein sobre las imprecisiones del lenguaje. No podemos perder de vista el hecho de que la esencia del Tractatus, al menos uno de ellos, es la búsqueda de un lenguaje objetivo y lógicamente desprovisto de imprecisiones.

Al argumentar que el significado de una proposición debe estar suficientemente definido, el Wittgenstein del Tractatus reconoce que el lenguaje está formado por imprecisiones, $\mathrm{y}$ que incluso lo que decimos no siempre es necesariamente preciso. Lo que hace en Tractatus es buscar un lenguaje lógicamente perfecto y puro $^{21}$, es decir, con una singularidad de significado de los símbolos; y para eso, concluirá que un lenguaje lógicamente perfecto tiene reglas de sintaxis que contribuyen a que los símbolos tengan un significado claro y único ${ }^{22}$.

En las investigaciones filosóficas, Wittgenstein tratará las reglas de una manera más sistemática y amplia, y aún menos enyesada desde un punto de vista lógico, por lo tanto, culminará en uno de sus principales postulados de su nueva forma de pensar sobre filosofía, de cómo resolver sus problemas. El contexto inicial es el de los juegos, no juegos de lenguaje todavía, sino juegos

21. Esta idea, como veremos a su vez, es lo que inspirará a Kelsen a buscar un concepto puro de derecho. Ver abajo, y en Kelsen (2009).

22. Wittgenstein (2008), Referencias que se pueden ver en la introducción del libro, realizada por su entonces amigo Bertrand Russel. 
en general, que también podrían, sin ningún problema, ser un contexto social.

El autor mantendrá que tales juegos consisten en mover cosas en una superficie de acuerdo con ciertas reglas, y para que uno no imagine de inmediato que el autor se refiere específicamente a los juegos de tablero, él mismo intenta deshacer cualquier error eventual, y agrega que no todos los juegos son como juegos de tableros (2009: $\S$ 3).

En el $§ 54$ de las Investigaciones, Wittgenstein explica por qué no hay necesidad, por ejemplo, de un catálogo de reglas para aprender a jugar. Según él:

“¡Pensemos en qué casos decimos que un juego se juega según una regla definida! La regla puede ser un recurso de la instrucción en el juego. Se le comunica al aprendiz y se le da su aplicación. - 0 es una herramienta del juego mismo. - 0: Una regla no encuentra aplicación ni en la instrucción ni en el juego mismo; ni es establecida en un catálogo de reglas. Se aprende el juego observando cómo juegan otros. Pero decimos que se juega según tales y cuales reglas porque un espectador puede extraer estas reglas de la práctica del juego - como una ley natural que sigue el desarrollo del juego (2009: § 3).

Es indiscutible que un texto de ley abierto y confuso, lleno de agujeros, es decir, de fallas, no puede considerarse un texto de ley, en la esencia del significado, porque no hace más que generar expectativa de norma, además de alimentar un infinito de interpretaciones, lo que lleva al ejercicio de la discreción de los encargados de hacer cumplir la ley: los jueces. Ahora, trayendo esta noción al estudio del lenguaje, realizada por Wittgenstein, encontraremos en §99 la mención de algo similar, pero en el contexto de oraciones, es decir, en el contexto gramatical.

Por lo tanto, el filósofo vienés dirá que las oraciones deben tener un significado definido, de lo contrario no serían oraciones, es decir, él necesita tener un límite definido, porque, según él, un límite inexacto no es, de hecho, ningún límite. Para Wittgenstein, cuando se dice, por ejemplo, que una persona estaba encerrada en una habitación, pero que solo quedaba una puerta abierta, en realidad está diciendo que nadie estaba encerrado en absoluto. Es decir, solo hay una apariencia de bloqueo (2009: § 99).

Al hacerlo, según nuestro filósofo, absolutamente nada de lo que se propuso o dijo que había hecho se habría hecho. Según él, "un corral que tiene un agujero vale tanto como ningún corral" (2009: § 99). En otras palabras, incluso puede ser un juego, es decir, incluso se puede decir que es un juego, pero no es específicamente, porque no es correcto, porque no se han seguido las reglas respectivas. Para Wittgenstein, "«...no es un juego si hay una vaguedad en las reglas»"23.

Al llevar esta noción a las leyes, sigue siendo evidente que no se tratan realmente de leyes, sino textos inexactos que deben devolverse al taller para una especie de Recall $L a w^{24}$, y que deben llevar a cabo los maestros (legisladores) del taller (parlamento) y no ser mantenidas en una plenitud deficitaria y sometidas a cualquier tipo de interpretación en una débil tentativa de arreglarlos con base en argumentos que no los mejoran en absoluto, simplemente intentan "explicarlos".

Por lo que hemos visto hasta ahora, es posible decir que no hay forma de hablar sobre el lenguaje sin hablar de reglas, y de la misma manera, no hay forma de hablar de derecho sin hablar de reglas, porque aquél presupone estas, y viceversa. A partir de las diversas concepciones filosóficas del Segundo Wittgenstein, especialmente las relacionadas con el seguimiento de las reglas, no es difícil imaginar que estas concepciones saldrán de la filosofía y entrarán en el Derecho "exigiendo" una nueva forma de verlo y conceptualizarlo o, cuando menos, hacer que sus estudiosos cuestionen su propia comprensión del derecho en una sociedad en constante cambio.

Sosteniendo una nueva forma de ver y hacer filosofía, basada en el análisis lingüístico fuera de los lazos lógico-positivistas, como se ve en el

23. Según este autor, es un juego contaminado, y considerarlo un juego en la plenitud de la palabra y lo que explicó que es un juego con reglas saludables es, de hecho, estar interesado en un juego que ha sido contaminado (2009: $\$ 99$ ).

24. Teniendo en cuenta que, en el recall, un fabricante se hace público para informar que su producto o servicio presenta riesgos para los consumidores, si agregamos otra palabra en inglés: Law (Ley), tendremos la idea de que el legislador ha entregado a la sociedad algunas leyes que deben revisarse, de ahí lo que se puede llamar, solo ilustrativamente, Recall Law, o simplemente: recuperación de leyes débiles. 
Wittgenstein del Tractatus, este filósofo vienés comienza a tratar la filosofía como un tipo de terapia para los problemas del lenguaje y del mundo. Según Juan Moreso, la filosofía está "llamada a curar ciertos tipos de trastornos intelectuales producidos por ciertas confusiones derivadas de nuestro uso del lenguaje" (Narváez Mora, 2004: 15$)^{25}$. No es de extrañar que, para Wittgenstein, "El filósofo trata una pregunta como una enfermedad” (Wittgenstein, 2009: § 255).

Habiendo hecho estas consideraciones, las puertas de la filosofía y la teoría del derecho a las concepciones de Wittgenstein se han abierto, y es en este contexto que comenzamos a analizar la influencia de este filósofo vienés en la concepción de Hart sobre el concepto de Derecho, pues, como dice el Dr. Moreso, "Wittgenstein es quizás el filósofo más grande del siglo XX"; y "no hay una esfera de filosofía en la que falte la proyección de las ideas de Wittgenstein" (Narváez Mora, 2004: 23).

Herbert Hart partirá de una idea pragmática sobre las reglas, ya que las reconoce como parámetros legales, cuyo propósito es el control social. Según Hart, "en cualquier grupo social grande, las reglas generales, los estándares y los principios deben ser el principal instrumento de control social, y no las directivas específicas dadas por separado a cada individuo" (1994: 137). Nuestro teórico reconoce la importancia de las reglas para el control social, como una condición para la existencia de la ley misma. Para Hart, "si no fuera posible comunicar estándares generales de conducta que multitudes de individuos pudieran percibir, sin más directivas, estándares que exigen cierta conducta de acuerdo con la ocasión, nada de lo que ahora reconocemos como un derecho podría existir" (Hart, 1994, 137) ${ }^{26}$.

25. Aún según Moreso, "este es el diagnóstico, y el remedio aparece muy claramente: debemos analizar los conceptos en sus determinados usos lingüísticos". Para Moreso, "así es como podemos entender la insistencia de WITTGENSTEIN en considerar el significado como el uso del lenguaje y de esta manera poder decir: "Nosotros reconducimos las palabras de su empleo metafísico a su empleo cotidiano" (WITTGENSTEIN (2009), § 116)". Idem, pp. 15/16.

26. La necesidad de estándares señalados por Hart hace que este autor tartamudee un sesgo sectario en relación con la sociedad y las personas que lo componen. Para él, la Ley debería referirse a categorías de personas y categorías de actos, cosas y circunstancias, sin embargo, no necesariamente de forma predominante, lo que en nuestra opinión no elimina el carácter sectario de la propuesta (Hart, 1994, 137).
Antes de pasar a la teoría de Hart, es importante hacer un pequeño paréntesis para abordar el origen del término "textura abierta" utilizado por Hart en su teoría. A ver.

\subsection{EL ORIGEN DEL TÉRMINO "TEXTURA ABIERTA".}

Waismann (1951), en un artículo de 1945, llamado Verifiability, es quien menciona el término "textura abierta" por primera vez, cuando critica la imprecisión de los conceptos jurídicos (Leer: imprecisión del lenguaje jurídica). Según él, la incapacidad de los fenomenólogos para traducir una declaración de objeto material en términos de datos de los sentidos no se debería, como se sugirió, a la pobreza de nuestro lenguaje, que no tenía el vocabulario para describir todos los detalles más mínimos de la experiencia sensorial, ni a las dificultades inherentes a la producción de una combinación infinita de declaraciones de datos sensoriales, aunque todas estas cosas podrían contribuir a esto. El problema del fracaso señalado se debería a un factor que, aunque era muy importante y obvio, nunca se había notado por la "textura abierta" de la mayoría de los conceptos empíricos (Waismann, 1951: 2).

Es importante tener en cuenta que, en el texto original, Waismann hace un punto al decir que él no es el autor del término "textura abierta", sinoKneale. El autor dirá expresamente en una nota al pie de página que: "Le debo este término ("textura abierta") al Sr. Kneale, quien lo sugirió como una traducción de Porosität der Begriffe, un término que acuñé en alemán"27. El hecho es que el término imaginado por Waismann no difiere mucho de la idea de una textura abierta, porque en una traducción literal del alemán al español tendríamos algo así como "porosidad de términos". Por lo tanto, dejando solo la idea de porosidad, de acuerdo con los diccionarios más diversos, tenemos que referirnos a los poros de un suelo, es decir, serían los espacios vacíos (poros) existentes entre las partículas sólidas.

27. WAISMANN (1951), 20, nota 2. Nuestros paréntesis. 'Señor Kneale fue William Kneale (1906-1990), un gran lógico inglés, especialmente interesado en la historia de la lógica. El trabajo de su vida fue desarrollar 800 páginas sobre lógica. Escribió este trabajo con su esposa Martha, y el libro se conoce comúnmente en el mundo académico como "Kneale and Kneale". Ver Dawid Bunikowski (2016): 1/24. Este es otro trabajo académico reciente que se ocupa del origen del término "textura abierta", de hecho, uno de los mejores y más completos sobre el tema. 
La idea de Waismann es usar este término para hablar de conceptos abiertos y explicarnos, pacientemente, trayendo un ejemplo sobre la definición de qué es el oro, o al menos su noción. Para nuestro autor, "el hecho de que en muchos casos no haya una verificación concluyente está relacionado con el hecho de que la mayoría de nuestros conceptos empíricos no están delimitados en todas las direcciones posibles" (Waismann, 1951: 3) ${ }^{28}$. Según él:

La noción de oro parece estar definida con absoluta precisión, por ejemplo, por el espectro de oro con sus líneas características. Ahora, ¿qué diría si se descubriera que una sustancia que parecía dorada satisface todas las pruebas químicas de oro mientras emite un nuevo tipo de radiación? "Pero estas cosas no suceden". Completamente así; pero pueden suceder, y eso es suficiente para demostrar que nunca podemos excluir totalmente la posibilidad de que surja una situación imprevista en la que tendremos que modificar nuestra definición.

Por mucho que lo intentemos, ningún concepto está limitado de tal manera que no haya lugar para ninguna duda. Introdujimos un concepto y lo limitamos en algunas direcciones; Por ejemplo, definimos el oro en contraste con otros metales, como las aleaciones. Esto es suficiente para nuestras necesidades actuales, y no vamos más allá. Tendemos a ignorar el hecho de que siempre hay otras direcciones en las que el concepto no se ha definido. Y si lo hiciéramos, fácilmente podríamos imaginar condiciones que requerirían nuevas limitaciones. En resumen, no es posible definir un concepto como el oro con absoluta precisión, es decir, de tal manera que cada esquina y rincón esté bloqueado contra la entrada o la duda. Eso es lo que significa la textura abierta de un concepto (Waismann, 1951: 3) (negrilla fuera del original).

28. Este autor dirá que "la textura abierta es una característica fundamental de la mayoría de los conceptos empíricos, aunque no de todos, y es esta textura la que nos impide verificar de manera concluyente la mayoría de nuestras afirmaciones empíricas". En este sentido, nuestro autor concluirá que "siempre habrá un margen de incertidumbre. Por lo tanto, la ausencia de verificación concluyente está directamente relacionada con la textura abierta de los términos en cuestión " (Waismann, 1951: 3).
El autor también busca eliminar cualquier duda o confusión que pueda surgir de su noción de textura abierta, explicando que es diferente de la imprecisión de un término, que es algo que puede variar de un sentido a otro, es decir, fluctúa en el contexto en el que se encuentra. utilizado Según él:

La indefinición debe distinguirse de la textura abierta. Se dice que una palabra que se usa realmente de manera flotante (como 'batería' o 'rosa') es vaga; un término como 'oro', aunque su uso real no es vago, no es exhaustivo o tiene una textura abierta, ya que nunca podemos llenar todos los vacíos posibles a través de los cuales puede penetrar una duda. La textura abierta, entonces, es algo así como la posibilidad de imprecisión. La inexactitud se puede remediar dando reglas más precisas, la textura abierta no. Una forma alternativa de decir esto sería decir que las definiciones de términos abiertos son siempre corregibles o modificables (Waismann, 1951: $3)^{29}$.

La idea de textura abierta puede compararse, por ejemplo, con expresiones que tienen una falta de comprensión por varias razones, pero aquí estamos interesados en la ausencia de posibilidades reales de ser entendidas o explicadas, y cuando lo son, no conducen a la voluntad de quienes la creó. Entonces serían expresiones incompletas porque tienen datos incompletos. Para estos tipos, Waismann dirá que son inferencias incompletas o incluso flojas. Según él:

En cierto sentido, podemos decir de una descripción de un objeto material que está incompleto; En otro sentido, podemos decir que conocemos las condiciones de contorno en un campo de fuerza. Hay un sentido en el que decimos que una lista de leyes de la naturaleza siempre está incompleta, y otro sentido en el que incluso nuestro conocimiento de los agentes de la naturaleza es así; y puedes encontrar más sentidos fácilmente. Todos se combinan, en un grado

29. Waismann, 1951, mantendrá enfáticamente que "Si no hubiera posibilidad (siempre presente) de la aparición de algo nuevo, no podría haber nada como la textura abierta de los conceptos; y si no existiera la textura abierta de los conceptos, la verificación sería incompleta solo en el sentido de que nunca podría completarse " $(p, 5)$ 
variable, para crear lo que he llamado la textura abierta de los conceptos y la laxitud de las inferencias (Waismann, 1951: 9).

Es importante no perder de vista el hecho de que la noción de textura abierta presentada en el artículo de Waismann se inserta notablemente en el contexto del lenguaje, que es, en gran medida, de qué trata su texto, las texturas abiertas en el lenguaje, y eso es sí, es filosofía del lenguaje La búsqueda del significado de las proposiciones, de las afirmaciones, como el de las propias reglas, desde las teorías del significado, propias o de terceros, siempre ha sido uno de los principales objetivos de quienes buscaban, desde los escritos de Wittgenstein, contribuir a la claridad de los procesos lingüísticos, es decir, de los problemas lingüísticos, que desde la filosofía del lenguaje, eran problemas filosóficos, y la preocupación por resolverlos y no expandirlos era y es el objetivo de los filósofos del lenguaje. Y esta preocupación ya se ve en el artículo del amigo de Wittgenstein. De acuerdo con Waismann,

Encontrarás que este es el hecho con el que a menudo se puede rastrear el surgimiento de problemas filosóficos. (Piense cuán confuso es afirmar o refutar la afirmación: "El terreno no es sólido", ya que pertenece a dos estratos muy distintos). Las líneas de fractura de los estratos del lenguaje están marcadas por problemas filosóficos: el problema de la percepción, la verificación, de inducción, el problema de la relación entre mente y cuerpo, y así sucesivamente (Waismann, 1951: 9).

Las reglas, si se observan desde el contexto de las proposiciones, también tienen su significado extraído del contexto en el que se usan, ya que también sufren de incompletitud en la medida en que son incomprensibles, ambiguas, abiertas y demasiado amplias. En este contexto, queda muy claro en Waismann, que él busca el significado de las declaraciones a partir de la aplicación de su teoría, que se parece más a un método de verificación, ya que defiende el empirismo como un medio para identificar el significado de las afirmaciones, desde el reconocimiento de las incompletitudes de tales afirmaciones. Según él,

La incompletitud, en los sentidos antes mencionados, es el sello distintivo del conocimiento empírico en oposición al conocimiento a priori, como la matemática.
De hecho, es el criterio por el cual podemos distinguir lenguajes perfectamente formalizados construidos por lógicos de lenguajes naturales como los utilizados para describir la realidad. En un sistema formalizado, el uso de cada símbolo se rige por un número definido de reglas y, además, todas las reglas de inferencia y procedimiento pueden declararse por completo. En vista de la incompletitud que impregna el conocimiento empírico, tal demanda no puede ser satisfecha por ningún lenguaje que podamos usar para expresarlo (Waismann, 1951: 9) ${ }^{30}$.

Habiendo explicado el origen de la creación del término "textura abierta" y en qué contexto fue utilizado por Waismann, veamos ahora hasta qué punto, tales manifestaciones del pensamiento waismanniano, apoyadas por Wittgenstein, fueron importantes para la construcción del pensamiento de Hart y su concepto de Derecho.

\subsection{DEL USO DEL TÉRMINO "TEXTURA ABIERTA" EN HART}

De las explicaciones ya mencionadas anteriormente, no hay duda de que Herbert Hart solo usó un nombre diferente, proveniente de la filosofía del lenguaje, precisamente del positivismo lógico del Círculo de Viena, del cual Waismann era (hacía) parte, para referirse a las brechas existentes en lenguaje jurídica. Si el término es "porosidad de términos" o "textura abierta", como lo sugirió su colega Kneale, no importa, ya que no le saca el mérito por la idea, el referencial que quería señalar, es decir, la existencia de agujeros en contextos lingüísticos, que tras de ser exportado a la teoría de Hart, se convirtió en el contexto del lenguaje jurídico, permaneciendo igual, por lo tanto, su esencia: el lenguaje.

A pesar de todas las dudas planteadas y las críticas que han recibido, la idea de "textura abierta" no puede ignorarse bajo ningún pretexto. Por nuestra parte, no vemos ningún problema

30. Para nuestro autor, "La existencia de una relación muy estrecha entre el contenido y la verificación es una idea importante que fue revelada por los empiristas. Solo tienes que tener mucho cuidado al formular esto. Lejos de identificar el significado de una declaración con la evidencia que tenemos de ella, la visión que intenté esbozar conduce a una especie de teoría del lenguaje de niveles múltiples en la que "cada tipo de declaración tiene su propio tipo de lógica" (Waismann, 1951: 9). 
en el uso de este término, siempre y cuando se refiera al lenguaje legal, pero no al Derecho en su conjunto, como lo hizo Hart, utilizándolo como una "textura abierta del Derecho", con lo que no podemos estar de acuerdo.

El primer lugar, si tomamos el escenario del ordenamiento jurídico como 'textura', como el tablero de un juego en particular, como lo imagina Waismann, algunos comentarios son necesarios seguidos de una conclusión casi elemental: Por una parte, es posible decir que existe una textura abierta en el sistema jurídico debido a la ausencia de metodologías efectivas y eficientes para aplicar el Derecho. Por otra parte, no puede perderse de vista el hecho de que existe una diferencia sustancial entre la textura abierta en el lenguaje jurídico, en los términos exactos en los que Waismann abogó, y la textura abierta en el Derecho, especialmente debido a la naturaleza abstracta del término Derecho. Se concluye entonces que es necesario conceptualizar primero el Derecho.

En segundo lugar, es necesario comprender preliminarmente lo que Hart quería decir cuando se refería al Derecho, ya sea a las leyes o al ordenamiento jurídico en su conjunto. Cuando hizo referencia a las leyes, y todo indica que lo hizo, sería correcto que, de acuerdo con sus propias concepciones ${ }^{31}$, el ordenamiento jurídico y los encargados de hacer cumplir las leyes (los aplicadores) deberían extraer las mejores explicaciones de allí (justificaciones); mientras que, cuando hizo referencia al ordenamiento jurídico, es saludable que comprendamos que ha caído en una trampa de abstracción, con la intención de referirse a las leyes, a las normas, es decir, al reglamento en general, y a haberse referido al Derecho en su conjunto.

Desde este punto de vista, es imperativo entender que lo que Hart dice tratarse de una textura abierta en el Derecho, de hecho, de acuerdo con sus propias concepciones y argumentos, se trata realmente es de una textura

31. Sobre esto, no creemos que las leyes deban explicarse, sino aplicarse y fundamentarse. Fundamentar es diferente de explicar. Esto está más cerca de hacer algo más claro, inteligible; mientras que esa, se acerca más a mostrar en qué se basa esta o aquella decisión. Debido a este sesgo, las decisiones deben ser fundamentadas, no explicadas. Una buena decisión, basada en buenas leyes (leyes bien hechas) es lo mismo que una buena broma, no necesita explicación. abierta del lenguaje jurídico. No hay escapatoria a esta conclusión. Y, en este contexto, volvemos a Waismann y, en consecuencia, a Wittgenstein, con sus problemas de filosofía resueltos, o al menos propuestos, obteniendo el significado de una palabra de su uso en el contexto ${ }^{32}$, lo que eliminaría, de una vez por todas, los agujeros en la norma sin la necesidad de interpretación y discreción sostenida por Hart, que, sin embargo, no resuelve el problema, sino que lo aumenta.

Para este pensamiento de Wittgenstein, es primordial concluir que el significado de cada palabra debe buscarse desde su contexto lingüístico, y esto debe observarse cuando se hacen las leyes. ¿Y a dónde nos llevaría esta conclusión elemental, si no a la realización de una necesidad urgente de recurrir a la reparación de leyes y normas en general a través de la legística?

\section{LA INFLUENCIA DE LA IDEA DE WITTGENSTEIN DE "SIGNIFICADO COMO USO" EN DWORKIN.}

\section{1 ¿¿DWORKIN, UN PRAGMÁTICO!?}

Una de las principales teorías del significado del Wittgenstein de las Investigaciones filosóficas, el significado como uso, también es utilizado en Dworkin como punto de partida para muchas de sus concepciones, que bien sellan su vena pragmática. ${ }^{33}$, a pesar de haber tomado posiciones críticas contra el pragmatismo ${ }^{34}$. Sobre

32. "El significado de una palabra es su uso en el lenguaje" (Wittgenstein, 2009: $\$ 43$ ).

33. Hablar de una vena pragmática en Dworkin es ciertamente controvertido con aquellos que conocen bien su trabajo, pero sin un sedimento cognitivo recomendable sobre la filosofía del lenguaje por Ludwig Wittgenstein, principalmente del segundo Wittgenstein, el de Investigaciones filosóficas, trabajo capital para la difusión y comprensión de lo moderno pragmatismo jurídico, ya que sirvió de base para los teóricos del siglo $\mathrm{XX}$, de lo que yo llamo la Escuela de Oxford, cuyos exponentes fueron filósofos como Ryle, Austin y muchos otros filósofos y teóricos estadounidenses, como Quine, entre otros, e incluido Ronald Dworkin. Así, es importante tener en cuenta que la idea en este trabajo no es desarrollar una tesis que respalde una hipótesis en la que Dworkin era o no un pragmatista disfrazado, sino solo señalar algunas influencias que también había sufrido de Wittgenstein.

34. Para Dworkin, "Como una concepción del Derecho, el pragmatismo no estipula que, entre estas diversas nociones de una buena comunidad, estén bien fundadas o sean atractivas. Alienta a los jueces a decidir y actuar según sus propios puntos de vista. Presupone que esta práctica servirá mejor a la comunidad acercándola a lo que es realmente una sociedad imparcial, justa y feliz, que cualquier otro programa alternativo que requiera coherencia con las decisiones ya tomadas por otros jueces o por 
esto, se recomienda el bien logrado trabajo de investigación del profesor Medauar Ommati, de PUC-Minas, Brasil, donde se observa un Dworkin pragmatista $^{35}$.

En su trabajo de investigación, después de hacer los argumentos que, en su opinión, respaldan y responden al título, este autor hace un resumen de los puntos relevantes que apuntan a un Dworkin anclado en concepciones pragmáticas $y$, como dijimos, en la idea de significado en Wittgenstein. Por lo tanto, destacamos solo dos de estos puntos, donde la relación de Dworkin con las ideas de Wittgenstein nos parece bastante clara. De acuerdo con Medauar Ommati:

a) El Derecho como integridad entiende el Derecho como una práctica interpretativa, imbuida de un propósito conferido por los participantes, es decir, los textos jurídicos son juegos de lenguaje y se transforman o incluso desaparecen a medida que se juegan;

b) En la medida en que las normas jurídicas deben interpretarse para hacer que el Derecho sea lo mejor posible (hipótesis estética de Dworkin), se debe prestar atención a la importancia del contexto para obtenerse la mejor comprensión que el texto puede aportar (Medauar Ommati, 2011: 115-137).

Dworkin sostiene en la introducción de su obra El Imperio de la Justicia, que sus ensayos proporcionan la estructura central de una teoría específica del derecho ${ }^{36}$, y ahí radica su reclamo, que es proponer una teoría general del derecho para los Estados Unidos de América. Para esta comprensión, es necesario reconocer que el objeto es la teoría misma del Derecho y el nicho, es decir, el contexto fáctico, son los Estados Unidos de América. Es decir, una teoría para uso exclusivo en los Estados Unidos, y que podría regir el Derecho aplicado allí. Por lo tanto, tenemos la idea del uso en el contexto. Y esta es una noción pragmática de aplicar una teoría del derecho.

Sin embargo, antes de continuar abordando la hipótesis de un Dworkin pragmatista, como una forma de demostrar que su idea de Derecho

la legislatura" (Dworkin, 1999: 186).

35. Medauar Ommati, 2011: 115-137.

36. DWORKIN (1999), 5, XIX. fue fuertemente influenciada por la idea del significado como uso, de Wittgenstein, es imperativo plantear, aunque sea de manera superficial, las características principales que permiten, sin duda, decir que este o aquel autor es pragmático o esta o aquella idea es pragmática.

En este sentido, tenemos que el pragmatismo como corriente filosófica se remonta a finales del siglo XIX, cuando William James (1844-1910), que era psicólogo, registró que este término había sido acuñado por Charles Sanders Peirce (1839$1914)^{37}$, uno lógico en ese momento. Ambos formaban parte de un grupo de intelectuales cuyo objetivo era especular sobre filosofía, sin embargo, desde un sesgo totalmente metafísico. Entonces, lo que se vio fue la filosofía estadounidense dando sus primeros pasos. Además de los ya mencionados, el grupo también contó con la colaboración de Oliver Wendell Holmes, Jr, (1841 - 1935).

Como es cierto, desde el comienzo de la historia, uno de los principales, si no el principal objetivo de la filosofía fue la búsqueda de la verdad, la explicación de las cosas, es decir, la búsqueda de respuestas a las razones de las cosas en el mundo. Bueno, el pragmatismo busca comprender la verdad de las cosas a partir del análisis del conjunto de sus consecuencias prácticas. Debería, entonces, observarse un sentido práctico. En este sentido, la verdad de las cosas surge de la utilidad social de lo que está idealizado. Por lo tanto, si las ideas y acciones de las personas no sirven a un propósito útil, entonces no sirven a la sociedad, no tiene ningún propósito, ya que no demuestran

37. Como dice el propio James William, "El término procede de la palabra griega $\pi \rho \alpha \gamma \mu \alpha$, que quiere decir acción, y de la que proceden nuestras palabras «práctica» y "práctico» l. Fue introducido por primera vez en la filosofía por el Sr. Charles Peirce en 1878. En un ensayo titulado "How to Make Our Ideas Clear", y publicado en el Popular Science Monthly de enero de ese año *, después de indicar que nuestras creencias realmente son reglas de acción, el Sr. Peirce afirmó que, para esclarecer el significado de un pensamiento, sólo necesitamos determinar qué conducta es adecuada para producirlo: tal conducta será para nosotros todo su significado. $Y$ el hecho tangible que está en la raíz de todas nuestras distinciones intelectuales, por sutiles que sean, es que ninguna de éstas es tan refinada como para no consistir sino en una posible diferencia en la práctica. Así pues, para lograr una perfecta claridad en nuestros pensamientos sobre un objeto, sólo necesitamos considerar qué efectos concebibles de índole práctica podría entrañar ese objeto, qué sensaciones hemos de esperar de él y qué reacciones habremos de preparar. Nuestra concepción de esos efectos, inmediatos o remotos, es nuestra concepción total del objeto, si es que esa concepción tiene algún significado real. Éste es el principio de Peirce, el principio del pragmatismo". (James, 2000: 80). 
ser ciertas. Finalmente, podemos decir que, por pragmatismo, el significado de los fenómenos se evalúa en función de su utilidad práctica.

Según De Wall, para Peirce, el pragmatismo es "un método para determinar el significado de conceptos, ideas, creencias, afirmaciones, proposiciones, etc., de cualquier cosa que pueda actuar como un signo" (De Waal, 2007: 40). Según Santaella, el pragmatismo "es un principio regulador de la lógica, que prescribe el entretenido examen de hipótesis" (Santaella, 1994: 138). En otra ronda, para James William, el pragmatismo consiste en "La actitud de apartarse de las realidades primeras, los principios, las «categorías»y las supuestas necesidades, y de dirigir las miras a lo que sucede más adelante, los frutos, las consecuencias, los hechos" (James, 2000: 85).

A partir de esta información, es posible señalar con seguridad que las principales características observadas en el pragmatismo son: a) El significado de algo, ya sea un concepto, una frase, una palabra o incluso un texto completo, está directamente relacionado con las consecuencias de su aplicación, es decir, de su uso; b) El significado de las cosas (léase: del todo) solo se puede encontrar en la utilidad práctica que genera; c) No hay imposición sobre las cosas, es decir, no se habla de verdades absolutas; y d) La validez de una creencia surge de los resultados prácticos logrados con su uso.

De hecho, Dworkin, 1999, (que también acude a ejemplos contrafactuales), al tratar las reglas de cortesía en su comunidad imaginaria, agregará que: "la cortesía requiere que los campesinos se quiten el sombrero ante los nobles" (p, 57). Según él, "durante algún tiempo, esta práctica tiene un carácter tabú: las reglas simplemente están ahí, y nadie las cuestiona ni intenta cambiarlas" ( $p$, 57). Por fin, nuestro autor no deja dudas de la inspiración pragmática al agregar que:

Todos desarrollan una actitud compleja" interpretativa "hacia las reglas de cortesía, una actitud que tiene dos componentes. La primera es la suposición de que la práctica de la cortesía no solo existe, sino que tiene un valor, sirve a algún interés o propósito, o refuerza algún principio - en resumen, tiene un propósito que puede afirmarse, independientemente de la mera descripción de las reglas que constituyen la práctica (Dworkin, 1999: 57). ${ }^{38}$

En la búsqueda de su concepto de Derecho, al tratar de las teorías que se originan en la filosofía del lenguaje, cuando agrega que "si las tratamos como teorías semánticas, ellas afirman que las reglas lingüísticas seguidas por los abogados toman proposiciones legales adyuvantes y predictivas" (Dworkin, 1999: 45), Dworkin reconocerá en este argumento que "la mejor versión sugiere que el significado exacto de una proposición jurídica - las condiciones bajo las cuales los abogados considerarán que la proposición es verdadera - depende del contexto" (Dworkin, 1999: 45). Tenemos, en este extracto, un ejemplo de defensa, incluso si fue involuntaria, aunque no lo parece, de una acción pragmática frente al significado de una proposición, donde el significado está condicionado al contexto de uso (significado como uso). También se puede considerar una contradicción del propio autor, quien imprime una dura crítica a los filósofos del lenguaje en el mismo trabajo, como si pudiera usar sus postulados y fundamentos sin darles el debido y merecido crédito ${ }^{39}$.

En otro giro, quien hace una fuerte defensa de las teorías que se originan de la filosofía del lenguaje y aun una crítica igualmente enérgica a Ronald Dworkin, es Narváez Mora, para quien "Dworkin usa la expresión" teorías semánticas del derecho" y presenta el problema de las llamadas "semantic sting" "40 para llevar a cabo

38. Otro punto en este contexto de utilidad como significado, claramente una característica pragmática, y que es utilizado por Dworkin, se puede ver en el extracto donde afirma que "cuando esta actitud interpretativa entra en vigor, la institución de la cortesía ya no es mecánica; ya no es deferencia espontánea a un orden de runas. La gente ahora trata de imponerle un significado a la institución, verlo con su mejor luz, y luego reestructurarlo a la luz de ese significado". DWORKIN (1999), 58.

39. Esto se puede ver cuando Dworkin trata el significado en relación con el derecho, cuando agrega: "Cuando los filósofos de lenguaje desarrollaron teorías de significado más sofisticadas, los filósofos del derecho se volvieron más cuidadosos en sus definiciones, y luego para afirmar que estaban describiendo el "uso" de conceptos jurídicos, con lo que significaban, en nuestro vocabulario, las circunstancias en las cuales las proposiciones jurídicas son consideradas verdaderas o falsas por todos los juristas competentes". Y luego, en una demostración de tal vez querer alejarse de las teorías que él mismo utiliza, el filósofo estadounidense, al estilo de nosotros y de ellos, o mejor dicho, de mí y de ellos, dispara: "En mi opinión, sin embargo, esto no fue mucho más que un cambio de empaque; en cualquier caso, tengo la intención de incluir las teorías sobre el "uso" en el grupo de teorías semánticas del derecho, así como las teorías anteriores, que tenían una definición más clara" (Dworkin, 2010: 40).

40. En una traducción literal sería algo como: picadura 
una desclasificación de ciertas filosofías jurídicas, manteniendo que sus intereses son ficticios en la medida en que "tomar los derechos en serio" nunca puede ser un tema de discusión semántica". Además, el autor continúa: "Si hay una manera errónea de entender la filosofía del lenguaje de Wittgenstein, esta es considerarla una discusión sobre 'palabras'” (Narváez Mora, 2004: 199).

Otra influencia sorprendente de Wittgenstein, y en este punto estamos de acuerdo con el profesor de PUC-Minas, Medauar Ommati (2017: 131), se puede ver cuando Dworkin afirma que:

El lenguaje solo puede adquirir significado a partir de hechos sociales, expectativas y las formas en que está presente, un hecho sintetizado en el tosco, slogan bien conocido, según el cual la clave del significado está en el uso. Esto es cierto no solo con respecto a la parte común y funcional de nuestro lenguaje, sino a todo, tanto la filosófica como la cotidiana (Dworkin, 2010: 57).

Es razonable decir que Dworkin defiende claramente actuar con pragmatismo al reconocer primero el alto grado de abstracción contenido en el lenguaje utilizado en algunos dispositivos presentes en la Constitución estadounidense $\mathrm{e}^{41}$ (a quien se dirige una buena parte de su doctrina), y en un segundo momento, defender la existencia de un significado claro, es decir, de un propósito, en la aplicación práctica de la norma. Para este autor, "está claro que hay desacuerdos acerca de la forma correcta en que estos principios morales abstractos deben enunciarse para aclararnos su significado y ayudarnos a aplicarlos a controversias políticas más concretas" (Dworkin, 2006: 11).

Con esta conciencia de los desacuerdos sobre la mejor manera de dar un sentido práctico, digamos, pragmáticamente, a la aplicación de la norma, debido al grado de abstracción ya señalado, Dworkin incluso reconoce la deficiencia de la lectura moral defendida por él, ante la cuantidad de normas contenidas en la constitución de su país, los Estados Unidos. Según él, "es evidente que la lectura moral no es

semántica, o incluso, toque semántico.

41. Según Dworkin, "muchos de estos dispositivos se filtran en un lenguaje moral excesivamente abstracto" (Dworkin, 2006: 10). adecuada para la interpretación de todo lo que contiene una constitución" (Dworkin, 2006: 11). Aún, según él, "la Constitución Estadounidense incluye muchos artículos y dispositivos que no son particularmente abstractos ni filtrados en el lenguaje de los principios morales" (Dworkin, 2006: 11).

Por supuesto, no podemos olvidar el trabajo en el que Dworkin (2010) dedica un capítulo entero a la cuestión del pragmatismo, de hecho, se dedica a criticar el pragmatismo, como hemos dicho anteriormente, sin embargo, a pesar de las feroces críticas y defensas del autor de un Derecho no pragmático, algunos de sus argumentos no pueden resistir un análisis comparativo más curioso, donde es evidente que Dworkin apoya ideas que son características de la corriente pragmática que inspiró a Wittgenstein en buena parte de sus Investigaciones filosóficas.

A partir de estos argumentos y sin perjuicio de tantos otros presentados por Dworkin, no hay duda de que este autor es de hecho un autor de tesis pragmáticas, sin embargo, no en la totalidad de los argumentos defendidos por los clásicos, ni, principalmente, por Rorty ${ }^{4}$, con quien Dworkin se enfrenta con sus diversos argumentos, sino un pragmático más moderado que aquellos, debido a su apego a las leyes y precedentes, es decir, a la jurisprudencia. En este sentido, está el artículo de Agudelo, donde sostiene que los pragmáticos clásicos, como William James y Dewey, "tienen sus visiones definidas en utilidad, en lo que es mejor, en el futuro de una comunidad, en el máximo deseable, etc., Dworkin, pretende todo esto, pero sin abandonar la ley y el precedente, situaciones que un pragmático serio, como Rorty, no le gustaría, todavía” (Agudelo, 2011: 129).

Se podrían incluir muchos otros ejemplos en este contexto, pero nos contentaremos con traer solo uno más, que resalte la vena dworkiana y la tendencia al pragmatismo, incluso si es el que él abogó, y como dijo Medauar Ommati, un pragmatismo más moderado. Así, en medio de su parábola de Hércules, uno de los críticos agregará:

42. El pensamiento de Rorty se puede encontrar en: RORTY, Richard. (2000) El pragmatismo, una versión. Traducción de Joan Vergés Gifra. Barcelona: Editorial Ariel. Las comillas en la palabra "favas" se deben a que en el artículo el autor (original en español) usa el término "carajo", que en portugués, en una traducción literal, correspondería a un "folle". 
Los buenos jueces saben que el significado claro de una ley clara, o de una regla bien definida que siempre se aplica y nunca ha sido impugnada en los precedentes, es el derecho, y que no hay nada que agregar. Sería ridículo, y no solo una pérdida de tiempo, someter estas verdades indiscutibles a pruebas de interpretación en cada ocasión (Dworkin, 1999: 128).

\subsection{DWORKIN BAJO LA INFLUENCIA WITTGENSTIANA}

Habiendo hecho estas consideraciones sobre el pragmatismo en Dworkin, que no es el objetivo específico de este trabajo académico, sin perjuicio de tantos otros fragmentos de su trabajo donde se observan características pragmáticas, lidiemos con la influencia de Wittgenstein en la filosofía de este filósofo estadounidense, y por eso, continuamos estudiando detenidamente el Imperio de la Justicia, donde la presencia de la filosofía Wittgenstiana es asombrosa, como veremos.

Desconsiderarlo o no, o simplemente citarlo y sacar provecho de sus postulados consciente o inconscientemente, la verdad es que la doctrina de Ronald Dworkin, especialmente su obra más destacada, El imperio de la justicia, está impregnada de concepciones Wittgenstianas, y no solo en con respecto al pragmatismo ya mencionado, sino toda la esencia de la filosofía de Wittgenstein, con respecto a sus principales bastiones filosóficos estampados en Investigaciones filosóficas, a saber: la idea de seguir las reglas; juegos de lenguaje; formas de vida; y significado como uso.

Hay muchas referencias que el filósofo estadounidense hace sobre cada uno de estos fenómenos traídos al mundo de la filosofía de una manera tan impactante por Wittgenstein. La idea, por ejemplo, de significado como uso, además de los extractos ya citados, está presente en varios pasajes del trabajo de Dworkin, como cuando se trata de Jurisprudencia Revisada, y hace una mención vibrante de la aplicación del lenguaje al contexto, es decir, de uso, al agregar que:

Nuestro lenguaje es lo suficientemente rico como para permitir un grado razonable de discriminación y elección de las palabras que usamos para decir lo que queremos decir, y nuestra elección, por lo tanto, dependerá de la pregunta que estamos tratando de responder, nuestra audiencia y el contexto en de lo que hablamos (Dworkin, 1999: 128).

En el mismo sentido, en medio de argumentos sobre la existencia de un "derecho nazi", a lo que agregará que "no necesitamos negar que el sistema nazi era un tipo de Derecho, cualquiera que sea la interpretación de nuestro propio Derecho que favorezcamos, porque hay un sentido válido en el que claramente era una cuestión de Derecho"43. Al tratar específicamente con la opinión de una persona que no estuvo de acuerdo en que el Derecho nazi no constituiría un derecho, Dworkin volverá a plantear la idea de utilizar la proposición en ese contexto. Según él, la opinión de esa persona, "ahora es un tipo especial de opinión política para la cual su lenguaje, si el contexto lo aclara, es completamente apropiado" (Dworkin, 1999: 129).

Con respecto a la flexibilidad del lenguaje legal, Dworkin llama la atención sobre las limitaciones del uso del lenguaje impuestas por el positivismo y las teorías semánticas, según él al "negar la oportunidad de usar la palabra" correcto "de esta manera flexible, dependiendo del contexto o el sentido" (Dworkin, 1999: 128). Nuestro autor también llama la atención sobre la importancia del contexto del objeto de la opinión de esa persona. Para él,

En ese caso, sería preferible la formulación alternativa" positivista "de su opinión, y nada nos justificaría limitar artificialmente nuestro lenguaje para que las opciones sensibles al contexto se vuelvan imposibles.

La sensibilidad al contexto es aún más importante cuando el tema en juego es más sensible, más especializado, más práctico que simplemente una cuestión de clasificación o crítica general de un sistema legal extranjero y muy diferente (Dworkin, 1999: 130).

Dworkin también reconoce la fugacidad de los contextos, es decir, la metamorfosis que ocurre constantemente, dado el dinamismo del Derecho mismo, lo que hace que también cambiemos nuestra percepción. Esto es, una vez más, una

43. Tenga en cuenta que este pensamiento es de naturaleza pragmática. Dworkin, 1999: 128. 
referencia clara a la idea de Wittgenstein de que el significado cambia dependiendo de su uso en contexto. En este sentido, Dworkin invita al lector al ejercicio de imaginarse a sí mismo como una autoridad romana de antaño. El autor dice:

Podemos tratar de ponernos completamente en la posición de las autoridades romanas, por ejemplo, y luego expresar nuestra opinión sobre lo que era el derecho romano, sin la tentación de agregar que, dado que el derecho romano apoyaba la esclavitud, no era un derecho completo, ni siquiera de ningún derecho. Omitimos la reserva porque nada, en el contexto de nuestro estudio, la hace pertinente. El contexto cambia nuevamente cuando pensamos que nuestro propio derecho es inmoral o injustificable, como un todo o en partes relevantes (Dworkin, 1999: 133).

Analizando las obras de Dworkin, principalmente El Imperio de la Justicia, no es difícil encontrar la presencia en exceso de muchos de los postulados de Wittgenstein, no solo desde el punto de vista estético, sino principalmente doctrinal, donde tenemos muchas probabilidades, tanto en el Tractatus, como en Investigaciones. Por lo tanto, si, por un lado, Dworkin pretendía que su teoría fuera una teoría general del derecho, es decir, resolver los problemas conceptuales del derecho e imponer un nuevo orden legal en los Estados Unidos, por otro lado, Wittgenstein, al final del Tractatus, deja en claro que su teoría positivista lógica resolvió todos los problemas de la filosofía, al menos era lo que él creía, como vimos anteriormente, en el aforismo 6.54.

Al sugerir que su propuesta tiene como objetivo demostrar una mejor teoría legal para los Estados Unidos de América (Dworkin, 1999: 5, XIX), uno tiene la idea del significado del derecho como uso, es decir, una defensa de que su teoría debe adaptarse al contexto, es decir, en el sistema legal de los EE.UU ${ }^{44}$. Tal perspectiva es totalmente pragmática, como defiende Wittgenstein.

También la comunidad ficticia imaginada por Dworkin para traernos la idea de las reglas de

44. Al sugerir que la comunidad estadounidense comenzó a trabajar con el Derecho imponiendo un propósito, una manera para hacer que esta práctica sea la mejor posible, Dworkin ya no dice que el Derecho estadounidense sea el producto de su uso, de sus experiencias prácticas de aplicación a casos específicos. cortesía no está lejos de la comunidad (tribu) imaginada por Wittgenstein para explicar la imposibilidad de un lenguaje privado ${ }^{45}$.

La idea de seguir reglas, que, como dijimos, es uno de los postulados de la filosofía del lenguaje de Wittgenstein, es tratada por Dworkin en más de tres docenas de ocasiones, como cuando agrega que:

(...) las proposiciones jurídicas no solo son ciertas debido a la autoridad de las personas a las que generalmente se obedece, sino, fundamentalmente, debido a las convenciones sociales que representan la aceptación, por parte de la comunidad, de un sistema de reglas que otorga a tales individuos o agrupa el poder de crear leyes válidas. ${ }^{46}$

Dworkin también utilizó las formas de vida, un término acuñado por Wittgenstein en Investigaciones filosóficas. De hecho, Dworkin menciona directa y expresamente a Wittgenstein en tres ocasiones en su obra El imperio de la Justicia. La primera, cuando se trata de la idea misma de una forma de vida, cuando dirá que:

"Esto significa no solo usar el mismo diccionario, sino compartir lo que Wittgenstein llamó una forma de vida suficientemente concreta, para que uno pueda encontrar significado y propósito en lo que el otro dice y hace, ver qué tipos de creencias y motivos entenderían su dicción, sus gestos, su tono de voz, etc. (Dworkin, 1999: 77).

45. Es la parábola muy comentada de la tribu WITTGENSTEIN. En este importante pasaje, el profesor de Cambridge dirá lo siguiente: "Una tribu que no conoce el concepto de dolor simulado. Quien expresa su dolor es compasivo. No conocen la actitud de desconfianza ante el dolor. Un extraño que cambia de nuestra cultura a esa cultura a menudo pensará que es una queja exagerada y que, incluso, solo persigue el propósito de provocar piedad; los nativos no parecen pensar eso. (Tienen en su idioma una expresión que corresponde, más o menos, con nuestra expresión de "sentir dolor"). Un misionero les enseña a estas personas nuestro idioma; durante este proceso los educa $y$, bajo su tutela, aprenden a distinguir entre una expresión auténtica y una expresión simulada de dolor. $Y$ si sospecha alguna expresión de dolor, la rechaza, enseñándoles a sospechar - Aprenden nuestra expresión "sentir dolor" y también "simular dolor". La pregunta es: ¿y si se les enseñara un nuevo concepto de dolor? Ciertamente no diría que solo ahora saben lo que es "dolor", porque si eso no significara que nunca habrían tenido dolor antes ". Ver (Wittgenstein, 1982: 203).

46. . 
Con respecto a la ley como integridad, Dworkin afirma que "diferentes formas de asociación presuponen diferentes tipos de interés general que, se cree, cada miembro debería tener hacia los demás" (Dworkin, 1999: 242-243). Se debe suponer que diferentes tipos de asociaciones requieren necesariamente diferentes tipos de lenguaje, ya que la diferencia es lo que los caracteriza como tales. Esto, en sí mismo, ya podría citarse como un ejemplo de la aceptación del postulado de Wittgenstein sobre las formas de vida, donde el filósofo vienés dirá que "imaginar un idioma significa imaginar una forma de vida". Sin embargo, nuestro autor va más allá y agrega que "dentro de la forma o forma de vida constituida por una práctica comunitaria, el interés debe ser general y proporcionar la base para responsabilidades más específicas" (Dworkin, 1999: 243). Para Dworkin,

(...) las asociaciones fraternales son conceptualmente igualitarias. Pueden ser estructurados, e incluso jerárquicos, de la misma manera que en una familia, pero la estructura y la jerarquía deben reflejar la suposición del grupo, que sus roles y reglas conciernen a los intereses de todos, y que la vida de una persona no es más importante que cualquier otra persona (Dworkin, 1999: 243).

Después de todo, sin perjuicio de tantos otros ejemplos, donde la idea del juego de lenguaje defendida por Wittgenstein es utilizada, a su manera, por Dworkin, vale la pena mencionar un extracto del tema dedicado al convencionalismo, donde este autor aborda lo seguimiento de reglas, citando las reglas del juego de ajedrez. Para él, es evidente que "las reglas de los juegos cambian con el tiempo. Pero, cuando estas reglas fueron aceptadas como una cuestión de convención, necesariamente se habrá hecho una distinción clara entre los argumentos sobre las reglas y los argumentos dentro de las reglas" (Dworkin, 1999: 167-168).

Teniendo en cuenta que antes de que se acepten las reglas, deben entenderse, porque de lo contrario no se hablará del juego, ya sea ajedrez o de cualquier otro tipo, tenemos ante nosotros lo esencial del argumento de Wittgenstein, cuando citó por primera vez su postulado sobre juegos de lenguaje, basados en el proceso de aprendizaje de idiomas por parte de los niños. Según Wittgenstein,

Podemos imaginarnos también que todo el proceso del uso de palabras es uno de esos juegos por medio de los cuales aprenden los niños su lengua materna. Llamaré a estos juegos «juegos de lenguaje» y hablaré a veces de un lenguaje primitivo como un juego de lenguaje $\mathrm{e}^{47}$.

La influencia de Wittgenstein en el pensamiento de Ronald Dworkin no puede medirse solo con las citas hechas en esta sección, sino que también puede demostrarse mediante la lectura total del filósofo y teórico estadounidense $^{48}$. Incluso se podría decir que son meras conjeturas, ya que no hay registro de la manifestación verbal del autor, sino solo pasajes, extractos que bien podrían significar algo más, en resumen. Sin embargo, esta no es la realidad, ya que es un hecho que Dworkin fue influenciado por la filosofía del lenguaje, aunque lo criticó, como hemos visto, $\mathrm{y}$, principalmente por la filosofía del lenguaje común, una corriente filosófica que, como hemos visto, reunió a importantes filósofos del lenguaje en segunda mitad del siglo XX. Para aquellos que aún son escépticos sobre esta influencia en Dworkin, el autor de El Imperio de la Justicia, cuando trata el tema de la jurisprudencia revisada, defiende que los jueces, al juzgar, dentro del alcance del Derecho Común, por supuesto, recurren a las reflexiones del Derecho dentro del alcance de la sociedad (de la demanda, del Derecho discutido), y no de eso fuera de ella. ${ }^{49}$ Para nuestro autor,

47. Agrega que también lo llamará "'"juego de lenguaje", el todo formado por el lenguaje y las acciones con las que se entrelaza". (Wittgenstein, 2009: $\$$ 7).

48. Solo para darle una ligera idea de la presencia de algunos postulados de Wittgenstein en el pensamiento de Dworkin, solo en el trabajo Imperio de la Justicia, tenemos los siguientes números: el término "significado" se usa en 70 ocasiones; el término "regla", en más de 100 ocasiones; el término "contexto", en más de 50 ocasiones; el término "idioma" más de 50 veces; "Usar" en más de cien ocasiones. Pero como se dijo, es solo para darte una idea.

49. Y $\quad$ en este punto, aquí hay una crítica a los jueces de países que no forman parte del Common Law, que, de la nada, deciden juzgar con base en la jurisprudencia de otros países, y lo que es peor, en base al derecho de otras sociedades, teniendo como resultado un Derecho transgénico y desfigurado, por no decir ajena, que de ninguna manera se ajusta al Derecho propio de la sociedad que está tratando de decir el Derecho (aplicar una sentencia). Es cierto que esto no está aplicando la Ley, ya que carece del mismo significado, que solo se puede encontrar en el contexto en el que se usa, no en otros contextos. Esto será tratado con mayor profundidad en trabajos posteriores de este autor. 
La práctica del precedente, que ningún juez puede ignorar por completo en su interpretación, presiona por el acuerdo; Las teorías de cada juez sobre lo que realmente significa juzgar incorporarán por referencia, a través de cualquier explicación y reelaboración del precedente en el que se basa, aspectos de otras interpretaciones actuales en ese momento. Además, los jueces reflexionan sobre la ley dentro de la sociedad y no fuera de ella (Wittgenstein, 1999: 110). ${ }^{50}$

De hecho, al defender que la base para la interpretación, de modo que se pueda producir un buen Derecho para obtener justicia es el entendimiento común de los miembros de la sociedad, el autor dice que la ley que importa es entendida por la sociedad misma, dentro y no fuera de ella, y esto debería aplicarse. Lo que defiende Dworkin es que las decisiones deben estar sujetas a un entendimiento común, y debido a esto agregará que "el entorno intelectual en general, así como el lenguaje común que refleja $\mathrm{y}$ protege este entorno, ejerce restricciones prácticas sobre el idiosincrasia y limitaciones conceptuales en la imaginación" (Wittgenstein, 1999: 110).

En otras palabras, aquí hay un Dworkin que se opone a la práctica que se ha vuelto común en algunos países, como Brasil, de que los jueces basen sus decisiones en la jurisprudencia, las tesis y las teorías que mejor se adapten a los países y sociedades que han sido formulados. Sin embargo, a expensas de las idiosincrasias y otras justificaciones se aplican fuera del ámbito social para el que fueron creadas.

\section{CONCLUSIONES}

Probablemente los reflejos de la influencia de la filosofía del lenguaje de Ludwig Wittgenstein sobre las teorías del derecho en Kelsen, Ross, Harty Dworkin no se agoten al final de esta investigación. Lo que es seguro es que la interacción dialéctica con la "teoría pura del derecho"; la idea de "fenómenos jurídicos como fenómenos sociales"; la "teoría de la textura abierta en el Derecho"; y la noción de "significado como uso", con un fuerte atractivo pragmático, respectivamente, nos permitió identificar la presencia de la filosofía del

50. Dworkin (1999), 110. lenguaje de Wittgenstein, en el pensamiento de estos magníficos autores.

En este artículo discutimos la filosofía del lenguaje del primer Wittgenstein (el del Tractatus Logico-Philosophicus) que inspiró a Hans Kelsen a concebir su teoría pura del derecho, a partir de la idea de una filosofía libre de dificultades lingüísticas, es decir, un lenguaje lógicamente perfecto, puro, sin los problemas recurrentes presentes en la filosofía tradicional. Vimos que este lenguaje ideal buscado por Wittgenstein sirvió a los propósitos de Kelsen, cuando defendió un "conocimiento puro", dirigido solo al Derecho, apoyando la exclusión de todo lo que no podía determinarse como un derecho.

En segundo lugar, se discutió lo importante que era para Alf Ross alejarse de esta abstracción normativa (respaldada por la idea de un lenguaje lógicamente perfecto), adoptada por Kelsen, para apoyar su concepto de Derecho, sin embargo, lo ha hecho desde el pensamiento del segundo Wittgenstein (el de las Investigaciones filosóficas), cuando pensó en los fenómenos jurídicos como fenómenos sociales, cuando concluyó que tales fenómenos son juegos de lenguaje.

Vimos que lo que destacaba en Ross era su noción de significado, cuando, basándose en la idea del significado como uso, mantenía que el significado atribuido a los símbolos lingüísticos está determinado por las costumbres de la comunidad, es decir, por las circunstancias y por el uso en el contexto, y este es el punto que consideramos más relevante en la conexión del pensamiento de Ross con el de Wittgenstein. Por lo tanto, se concluye, en este punto, que este pensamiento ocurre dentro del alcance de una filosofía del lenguaje ordinario y, por lo tanto, se separa del positivismo lógico apoyado por Kelsen.

En el mismo sentido, después de visitar el pensamiento de Herbert Hart, concluimos que este autor, considerando las reglas como parámetros legales, cuyo propósito principal es el control social, dejó en claro que su concepción estaba anclada en la filosofía del lenguaje de Wittgenstein, porque, al reconocer la existencia de una textura abierta en el lenguaje jurídica, no hace más de lo que Wittgenstein ya había hecho al plantear la existencia de problemas filosóficos, como problemas de lenguaje, confusiones derivadas del papel del filósofo mismo, y fue a 
partir de esta idea que Hart construyó su concepto de derecho.

También sostenemos que las reglas, si se observan desde el contexto de las proposiciones, tienen su significado extraído del contexto en el que se usan, ya que sufren incompletudes cuando son incomprensibles, ambiguas, abiertas y muy amplias. En este sentido, la conclusión es que cuando Hart trata con la idea de una textura abierta en el Derecho, en realidad trata con la idea de una textura abierta en el lenguaje jurídico, $\mathrm{y}$ en este punto yace el enlace a las ideas de Wittgenstein sobre las reglas y el significado de las proposiciones del contexto.

Finalmente, después de investigar el trabajo de Ronald Dworkin, concluimos que ideas como la de los juegos de lenguaje; seguir reglas; formas de vida y el significado como uso, de Ludwig Wittgenstein, están presentes sistemáticamente en el pensamiento de este teórico. Y no nos basamos solo en un sesgo pragmático, como el que el autor defiende la existencia de un significado y un propósito claros cuando se trata de la aplicación práctica de la norma ${ }^{51}$, ni como el que sugiere que el significado de una proposición jurídica depende del contexto ${ }^{52}$ donde se insertan, pero en un marco completo de evidencias que fue discutido y contextualizado en este trabajo, cuando tratamos con Dworkin. Así, se hizo evidente que su concepto de Derecho está anclado en la filosofía del lenguaje, especialmente en lo que surgió del centro del movimiento filosófico pragmático, tanto en los Estados Unidos como en la Escuela de Oxford.

Dado lo anterior, concluimos que, en mayor o menor medida, la verdad es que la filosofía Wittgenstiana está allí, bien o mal interpretada, pero está presente en las principales obras filosóficas y teóricas del Derecho, y esto no se puede negar. No es, por lo tanto, una ola, sino un hecho que no puede ser ignorado por las Escuelas de Derecho, por los teóricos de hoy y, en consecuencia, por los nuevos investigadores, ya que son teorías como las que fueron objeto de este trabajo, que tienen dado un nuevo significado a la filosofía, y creemos que aquí es donde va la filosofía del derecho, a una realidad jurídica donde la base está actualmente sedimentada por el pensamiento filosófico de Ludwig Wittgenstein, sin embargo, dentro del alcance de las Investigaciones filosóficas, ya que la teoría de Kelsen, concebida bajo los auspicios del Tractatus, ha sido cuestionada durante mucho tiempo y ha estado perdiendo cada vez más espacio como una teoría fuerte del derecho.

Después de todo, la intención del artículo es que investigaciones sobre este tema continúen surgiendo a manos de otros autores, quienes probablemente profundizarán en la influencia de la filosofía de Ludwig Wittgenstein en la teoría del derecho, a partir del pensamiento de tantos otros teóricos del Derecho en la actualidad. Entonces, que vengan y contribuyan con la evolución del Derecho, como un todo.

51. Dworkin, 2006: 11).

52. Dworkin (2010: 45).

\section{REFERENCIAS BIBLIOGRÁFICAS}

- Agudelo, C. A. (2011). "La justicia con toga" de Ronald Dworkin: ¿Los jueces son filósofos o son intérpretes moderados? Revista de Investigaciones Sophia, (7): 129144. Disponível em http://bit.ly/2yazefK.

- Apel, K. O. (2013). Paradigmas de Filosofia primeira. Trad. Andrés Crelier e Miguel Mailluquet. Buenos Aires: Prometeo Libros.

- Austin, J. (1962) How to do things with words. The William James lectures delivered at Harvard University in 1955. Oxford: Clarendon Press.

- Dawid Bunikowski, J. (2016). The Origins of Open Texture in Language and Legal Philosophies in Oxford and Cambridge. Rechtstheorie 47. Berlin: Duncker \& Humblot.

- De Waal, C. (2007). Sobre pragmatismo. São Paulo: Loyola.

- Dworkin, R. (1999). 0 império do Direito. 
São Paulo: Martins Fontes.

- _. (2006). O Direito da Liberdade: A Leitura Moral da Constituição NorteAmericana. Trad. Marcelo Brandão Cipolla. São Paulo: Martins Fontes.

- _ـ (2010). A Justiça de Toga. São Paulo: Martins Fontes

- Fossi, J. (2014). Conceptos jurídicos. Lecciones de teoría del derecho. Venezuela: Editorial Livrosca.

- Hart, H. L. A. (2001). O conceito de Direito. Tradução de A. Ribeiro Mendes, do original The Concept of Law. 3ํㅡㄹ Edição. Lisboa: FCG.

- James, W. (2000) Pragmatismo. Un nuevo nombre para viejas formas de pensar. Trad. de Ramón de Castillo. Madrid: Alianza Editorial, S/A.

- Kelsen, H. (1999). Teoria pura do direito. Tradução de João Baptista Machado. 6⿳a ed., São Paulo: WMF Martins Fontes.

- _ _ (2009). Teoría pura del Derecho. Traducción Moisés Nilve. $4^{a}$ ed., Buenos Aires: Eudeba.

- Machado, R. D. A Influência de Ludwig Wittgenstein no pensamento de H. L. Hart. Revista de Estudos Jurídicos - UNA, Vol. 2, no 1 (2015). Consultado em 23 de julho de 2019 http://bit.ly/2Z06DJg.

- Maia, A. (2006). Kelsen e a filosofia da linguagem de Wittgenstein: um estudo comparado do Tractatus LogicoPhilosophicus e das Investigações Filosóficas sobre a teoria pura do direito. Dissertação de Mestrado Pontifícia Universidade Católica de Minas Gerais. Consultado em 05 de junho de 2019 em http://bit.ly/2TepgnC.

- Medauar Ommati, J. E. (2011). Ronald Dworkin Pragmatista? Aproximações entre a Teoria do Direito como Integridade, de Ronald Dworkin, e o Pragmatismo de Ludwig Wittgenstein. Revista Eletrônica do Curso de Direito, (03): 115 - 137. Consultado em 11 de julho de 2019 em http://bit. ly/2OPK3yY.

- Narváez Mora, M. (2004). Wittgenstein y la teoría del derecho. Una senda para el convencionalismo jurídico. Barcelona: Marcial Pons, Ediciones Jurídicas y Sociales, S. A.

- Oliveira, D. B. (2017). Reviravolta linguísticopragmática na filosofia contemporânea. Revista de Estudos Constitucionais, Hermenêutica e Teoria do Direito, RECHTD, 9 (1): 33-41. Consultado em 05 de junho de 2019 em http://bit.ly/31M8rUR.

- Oliveira, M.A. de. (2006). Reviravolta linguístico-pragmática na filosofia contemporânea. $3^{a}$ ed., São Paulo: Edições Loyola.

- Ouelbani, M. (2009). 0 Circulo de Viena. São Paulo: Parábola.

- Rémi F. (2017). L'émergence de l'idée de progrès des connaissances en chimie. Halshs-01906647f (4) : 12 - 14. Consultado em 07 de agosto de 2019 em: http://bit. ly/2Km2jMo.

- Ross, A. (2000). Direito e Justiça. Bauru: Edipro.

- Rudá, A. S. (2019). Fundamentos de la Teoría Significativa de la Imputación. Barcelona: Bosch.

- Russell, B. (1959). My Philosophical Development. London: Allen \& Unwin.

- Santaella, L. (1994). Semiótica, 1994, 11 ed. São Paulo: Brasiliense.

- Saussure, F. (2006). Curso de Linguística Geral. Org. Charles Bally e Albert Sechehaye. São Paulo: Cultrix.

- Schambeck, H. (1994). «Merkl, Adolf Julius». Neue Deutsche Biographie (NDB). 17. ed. Berlim: Duncker \& Humblot.

- Schleiermacher, F. (1982). On the Different Methods of Translation. In: Willson, A. Leslie. German: Romantic Criticism.

- Stolz, S. (2007). Um modelo de positivismo jurídico: o pensamento de Herbert Hart. Revista Direito GV, 3 (1): 101-120.

- Struchiner, N. (2001). Uma análise da textura aberta da linguagem e sua aplicação ao Direito. Dissertação de Mestrado. Pontifícia 
Universidade Católica do Rio de Janeiro.

- Universidad del Norte. (2007). La formación básica en la Universidad del Norte. Barranquilla: Ediciones Uninorte.

- Villanueva, L. M. (2012). La Búsqueda del Significado. Edição de 2005, reimpressão de 2012. Madrid: Editorial Tecnos, S.A.

- Waismann, F. (1947). Verifiability. Em: Antony Flew, ed., Logic and Language, the First Series (1951), Originally published in Proceedings of the Aristotelian Society, Supplementary Volume XIX (1945). Journal of Symbolic Logic, 12 (3):101-101.
- Winch, P. (1990). The idea of a Social Science and is Relation to Philosophy. London: Routledge and Kegan Paul.

- Wittgenstein, L. (1982). Últimos Escritos sobre filosofia de la Psicología. Tradução de Edmundo Fernández, Encarna Hidalgo y Pedro Mantas. Lisboa: Edições 70

- ___ (2008). Tractatus Logico-Philosophicus. Trad. de Luis Henrique Lopes dos Santos. São Paulo: Editora da Universidade de São Paulo.

- __ (2009). Investigações Filosóficas, trad. de Marcos G. Montagnoli. Petrópolis: Vozes. 